\title{
The Complex Hodological Architecture of the Macaque Dorsal Intraparietal Areas as Emerging from Neural Tracers and DW-MRI Tractography
}

\author{
Roberto Caminiti, ${ }^{1}$ Gabriel Girard, ${ }^{2,3,4}$ ๑Alexandra Battaglia-Mayer, ${ }^{5}$ Elena Borra, ${ }^{6}{ }^{\circledR}$ Andrea Schito, ${ }^{5,7}$ \\ Giorgio M. Innocenti, ${ }^{4,8,9, \dagger}$ and ${ }^{-}$Giuseppe Luppino $^{6}$
}

https://doi.org/10.1523/ENEURO.0102-21.2021

\begin{abstract}
${ }^{1}$ Neuroscience and Behavior Laboratory, Istituto Italiano di Tecnologia, Rome 00161, Italy, ${ }^{2} \mathrm{CIBM}$ Center for Biomedical Imaging, Lausanne $\mathrm{CH}-1015$, Switzerland, ${ }^{3}$ Radiology Department, Centre Hospitalier Universitaire Vaudois and University of Lausanne, Lausanne $\mathrm{CH}-1011$, Switzerland, ${ }^{4}$ Signal Processing Laboratory (LTS5), École Polytechnique Fédérale de Lausanne, Lausanne, $\mathrm{CH}-1015$ Switzerland, ${ }^{5}$ Department of Physiology and

Pharmacology, University of Rome SAPIENZA, Rome 00185, Italy, ${ }^{6}$ Dipartimento di Medicina e Chirurgia, Università di Parma, Parma 43125, Italy, ${ }^{7} \mathrm{PhD}$ Program in Behavioral Neuroscience, University of Rome SAPIENZA, Rome 00185, Italy, ${ }^{8}$ Department of Neuroscience, Karolinska Institutet, Stockholm 171 1777, Sweden, and ${ }^{9}$ Brain and Mind Institute, École Polytechnique Fédérale de Lausanne, Lausanne $\mathrm{CH}-1015$, Switzerland
\end{abstract}

\section{Visual Abstract}
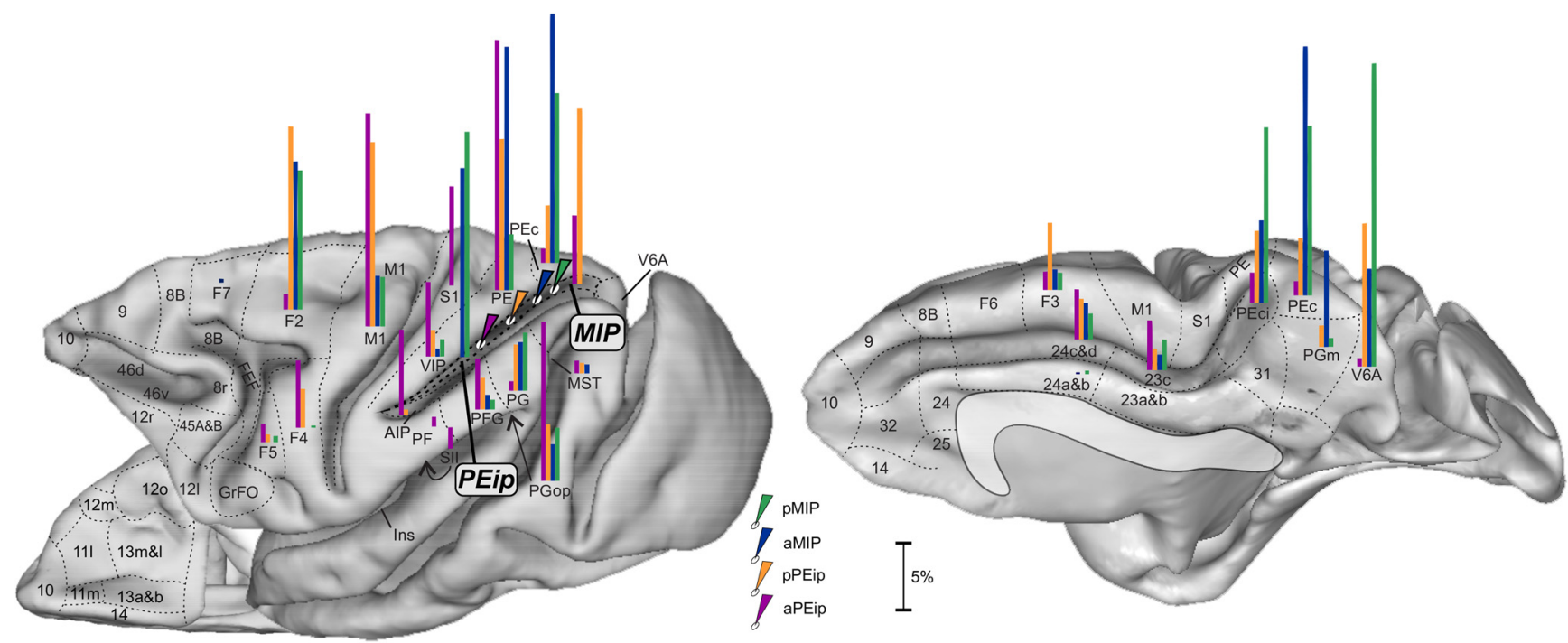

In macaque monkeys, dorsal intraparietal areas are involved in several daily visuomotor actions. However, their border and sources of cortical afferents remain loosely defined. Combining retrograde histologic tracing and MRI diffusion-based tractography, we found a complex hodology of the dorsal bank of the intraparietal sulcus (db-IPS), which can be subdivided into a rostral intraparietal area PEip, projecting to the spinal cord, and a caudal medial intraparietal area MIP lacking such projections. Both include an anterior and a posterior sector, emerging from their ipsilateral, gradient-like connectivity profiles. As tractography estimations, we used the cross-sectional area of the white matter bundles connecting each area with other parietal and frontal regions, after selecting regions of interest (ROIs) corresponding to the injection sites of neural tracers. For most connections, we found a significant correlation between the proportions of cells projecting to all sectors of PEip and MIP along the continuum 


\section{Significance Statement}

Combined histologic and diffusion-weighted MRI (DW-MRI) tractography revealed that areas PE intraparietal (PEip) and Medial intraparietal (MIP) share common inputs from other parietal, frontal and, to a lesser extent, cingulate areas, although with different gradient-like connectivity profiles. Both tractography and histology revealed a high number of common paths, although tractography showed false positive connections awaiting histologic validation. A correlation was performed between the proportion of labeled cells projecting to PEip and MIP and the diffusion-based connectivity estimation of the regions of interest (ROIs) corresponding to the injection sites of retrograde tracers. The results showed a significant correlation from most connections studied, opening a window for future studies contrasting proportions of cells, giving rise to the fiber bundles connecting cortical areas, with measures of diffusion tractography connectivity.

of the db-IPS and tractography. The latter also revealed "false positive" but plausible connections awaiting histologic validation.

Key words: cortico-cortical connections; diffusion tractography; frontal cortex; intraparietal sulcus; macaque brain; parietal cortex

\section{Introduction}

Areas PE intraparietal (PEip) and medial intraparietal (MIP) in the dorsal bank of the intraparietal sulcus (dbIPS) of monkeys are two crucial nodes for controlling visuomotor behavior. This view stems from different sources of information. The first relates to their input-output relationships (Johnson et al., 1996; Caminiti et al., 1996; Matelli et al., 1998; Marconi et al., 2001; Bakola et al., 2017; Battaglia-Mayer and Caminiti, 2018, 2019), since they receive projections from visuomotor areas V6A and PGm and project to premotor and motor cortex (see Caminiti et al., 2017). The second consists in the functional properties of their neurons (see Lacquaniti et al., 1995; Johnson et al., 1996; Batista et al., 1999), which combine retinal signals about target location, with eye and hand position and movement directions within their tuning fields (Battaglia-Mayer et al., 2000, 2001). The third stems from the consequences of lesions of parieto-

Received March 15, 2021; accepted May 1, 2021; First published May 26, 2021.

The authors declare no competing financial interests.

Author contributions: R.C., A.B.-M., E.B., G.M.I., and G.L. designed research; R.C., G.G., A.B.-M., E.B., A.S., and G.L. performed research; R.C., G.G., A.B.-M., and G.L. wrote the paper; G.G., A.B.-M., E.B., A.S., G.M.I., and G.L. analyzed data.

This work was supported by the Ministero dell'Istruzione, dell'UNiversità e della Ricerca of Italy PRIN 2017 Grants 201794KEER_002 (to A.B.-M.) and 2017KZNZLN_002 (to E.B.). This work was also supported by the Istituto Italiano di Tecnologia (R.C.). The CIBM Center for Biomedical Imaging was supported by Lausanne University Hospital (CHUV), University of Lausanne (UNIL), Ecole Polytechnique Fédérale de Lausanne (EPFL), University of Geneva (UNIGE), and Geneva University Hospitals (HUG).

This paper is dedicated to our co-author and friend Giorgio M. Innocenti, who passed away unexpectedly on January 12, 2021.

${ }^{\dagger}$ Deceased, Jan. 12, 2021.

Correspondence should be addressed to Roberto Caminiti at roberto. caminiti@uniroma1.it.

https://doi.org/10.1523/ENEURO.0102-21.2021

Copyright (C) 2021 Caminiti et al.

This is an open-access article distributed under the terms of the Creative Commons Attribution 4.0 International license, which permits unrestricted use, distribution and reproduction in any medium provided that the original work is properly attributed. occipital areas in humans, consisting in a defective visual control of reaching, known as optic ataxia (Bálint, 1909; see Rossetti and Pisella, 2018).

To date, aspects of PEip and MIP connectivity remain unknown, since the difficulty of injecting histologic tracers over the entire dorsoventral (D-V) extent of the IPS rendered only a partial view of its connectivity. Previous attempts to mark the PEip/MIP border were based on the presence of cortico-spinal projections (Matelli et al., 1998) or on myeloarchitectonic criteria (Bakola et al., 2017). Based on cytoarchitectonics, Pandya and Seltzer (1982) labeled this region of the superior parietal lobule (SPL) as area $\mathrm{PEa}$, to distinguish it from the remaining part of area 5. This study was, however, antecedent to the identification of MIP as the dorsal intraparietal region projecting to area PO (Colby et al., 1988).

The difficulties of histologic studies can tentatively be overcome by diffusion-weighted MRI (DW-MRI) tractography. Albeit known limitations, such as the identification of false-positive connections and biases toward reconstructing short and strong connections (Jones et al., 2013; Van Essen et al., 2014; Jbabdi et al., 2015; Knösche et al., 2015; Maier-Hein et al., 2017; Aydogan et al., 2018; Jeurissen et al., 2019; Schilling et al., 2019a,b; Girard et al., 2020), tractography shows promising results when compared with histology (Dauguet et al., 2007; Dyrby et al., 2007; Seehaus et al., 2013; Jbabdi et al., 2015; Thomas et al., 2014; Azadbakht et al., 2015; Calabrese et al., 2015; Gyengesi et al., 2015; van den Heuvel et al., 2015; Knösche et al., 2015; Donahue et al., 2016; Delettre et al., 2019; Ambrosen et al., 2020; Girard et al., 2020). Particularly, Calabrese et al. (2015), Donahue et al. (2016), and Ambrosen et al. (2020) have reported positive results when comparing labeled cells count from tracer injections in the monkey brain with connectivity weights derived from DW-MRI tractography.

In this study, we combined tractography and histology to elucidate the connectivity of PEip and MIP. In two macaque monkeys, we injected different retrograde fluorescent tracers along the antero-posterior $(A-P)$ extent of the 
$\mathrm{db}$-IPS and established their putative border based on the distribution of cortico-spinal cells projecting to the cervical segments of the spinal cord, as determined in two other animals (see Matelli et al., 1998). The connectivity of the db-IPS was studied with tractography in a fifth animal and compared in a quantitative fashion with histologic data. To explore potential connections of PEip and MIP not yet revealed by tract tracing studies, the $D-V$ extent of these areas was subdivided into different regions of interest (ROIs). This was inspired by earlier anatomo-functional studies (Johnson et al., 1996; Battaglia-Mayer et al., 2001) showing systematic changes of both functional properties and corticocortical connectivity in the D-V extent of the intraparietal cortex.

Combining histology and tractography revealed a significant correlation between the proportion of cells projecting to MIP and/or PEip and the diffusion-based connectivity estimates of the corresponding streamlines. Furthermore, tractography resulted to be very useful in revealing aspects of parietal connectivity which could not be explored based on neural tracer injections. Beyond advancing the information about cortical connectivity of the IPS, these results offer a quantitative cross-validation of the two methods and call for a histologic validation of predictions emerging from tractography.

\section{Materials and Methods}

\section{Neural tracer experiments \\ Subjects}

The tracer experiments were conducted in four male monkeys. In two animals (Macaca mulatta; cases 72 and 73; body weight 12 and $12.50 \mathrm{~kg}$, respectively) retrograde neural tracers were injected at different A-P levels of the $\mathrm{db}$-IPS. Additional data from two Macaca nemestrina (cases 10 and 21; body weight 5.2 and $4.4 \mathrm{~kg}$, respectively), in which a retrograde tracer was injected in the lateral funiculus of the spinal cord, were used for visualizing the origin of corticospinal projections from the db-IPS. Data from these two cases have been already partially used in previous studies (Luppino et al., 1994; Matelli et al., 1998; Rozzi et al., 2006; Borra et al., 2010).

Animal handling as well as surgical and experimental procedures complied with the European law on the humane care and use of laboratory animals (Directives 86/ 609/EEC, 2003/65/CE, and 2010/63/EU) and the Italian laws in force regarding the care and use of laboratory animals (D.L. 116/92 and 26/2014). All procedures were approved by the Veterinarian Animal Care and Use Committee of the University of Rome SAPIENZA or of the University of Parma, and then authorized by the Italian Ministry of Health.

\section{Surgical procedures}

Surgery was performed under aseptic conditions. Cases 72 and 73 were preanaesthetized with ketamine $(5 \mathrm{mg} / \mathrm{kg}$, i.m.) and dexmedetomidine hydrochloride $(0.1 \mathrm{mg} / \mathrm{kg}$, i.m.), intubated and anaesthetized with a mix of oxygen/isoflurane (1-3\% to effect). Lidocaine (2\%) was used locally to minimize pain during skin incision in the scalp. Desametasone $(6 \mathrm{mg} / \mathrm{kg})$ was given before dura opening, to prevent brain inflammation and edema. The skull was then trephined over the target region, and the dura was opened to expose the intraparietal sulcus. A constant infusion of Fentanil $(0.2 \mathrm{mg} / \mathrm{kg} / \mathrm{h}$, i.v.) was performed until the end of the surgical procedures. The selection of the injection sites was based on identified anatomic landmarks, such as the rostral tip of the IPS. In cases 10 and 21, in which tracers were injected in the spinal cord, under general anesthesia $(5 \mathrm{mg} / \mathrm{kg}$ ketamine, i. $\mathrm{m}$., and $0.08-0.1 \mathrm{mg} / \mathrm{kg}$ medetomidine, i.m.), following a laminectomy, the dura was opened, and the segment of the spinal cord selected for the injection exposed. During all surgeries, hydration was maintained with saline, and temperature using a heating pad. Heart rate, blood pressure, respiratory depth, $\mathrm{O}_{2}$ saturation, and body temperature were continuously monitored.

\section{Tracer injections}

Once the appropriate site was chosen, fluorescent tracers [fast blue (FB) $3 \%$ in distilled water, diamidino yellow (DY) $2 \%$ in $0.2 \mathrm{~m}$ phosphate buffer at $\mathrm{pH} 7.2$, both from Illing Plastics $\mathrm{GmbH}$ ] were slowly pressure injected with a glass micropipette attached to the needle of a Hamilton microsyringe at different depths and A-P levels in the medial bank of the IPS. In case 72 (Fig. 1), FB (two deposits, $0.15 \mu \mathrm{l}$ each, at a depth of 3 and $4 \mathrm{~mm}$, in the anterior part of area MIP, aMIP) and DY (two deposits, $0.15 \mu \mathrm{l}$ each, at a depth of 3 and $4 \mathrm{~mm}$, in the posterior part of area PEip, pPEip) were injected at $\sim 16$ and $13 \mathrm{~mm}$ caudal to the rostral end of the right IPS, respectively. In case 73 (Fig. 1), FB $(0.3 \mu \mathrm{l})$ and DY $(0.3 \mu \mathrm{l})$ were injected at a depth of 4 $\mathrm{mm}$, caudal to the rostral end of the left IPS, at $\sim 8.5 \mathrm{~mm}$ (in the anterior part of area PEip, aPEip) and $18 \mathrm{~mm}$ (in the posterior part of area MIP, pMIP), respectively. To facilitate comparison of the data with case 72 , the brain in case 73 is shown as a right hemisphere. After the tracer injections were placed, the dura flap was sutured, the bone was replaced, and the superficial tissues were sutured in layers.

In cases 10 and 21 the retrograde tracer horseradish peroxidase (HRP; $30 \%$ in $2 \%$ lysolecithin, Sigma-Aldrich) was pressure injected with a $5-\mu l$ Hamilton microsyringe in the left lateral funiculus in both monkeys (Fig. 2). In one animal (case 10), the tracer (multiple injections, total amount $10 \mu \mathrm{l}$ ) was injected at the C4-C5 spinal level, in the other (case 21, multiple injections, total amount $15 \mu \mathrm{l}$ ) at C3-C5 level. Upon the completion of the injections, the spinal cord was covered with Gelfoam and wounds were closed in layers.

Upon recovery from anesthesia, the animals were returned to their home cages and closely monitored. Dexamethasone and prophylactic broad-spectrum antibiotics were administered preoperatively and postoperatively. Furthermore, analgesics were administered intraoperatively and postoperatively.

\section{Histologic procedures}

At the end of the survival time ( $26 \mathrm{~d}$ for case $72 ; 23 d$ for case 73; $3 \mathrm{~d}$ for cases 10 and 21), the animals were given a dose of atropine (0.4 ml, i.m.) and diazepam (2 $\mathrm{ml}$ valium, i.m.), preanaesthetized as above, and received an 
Case 72

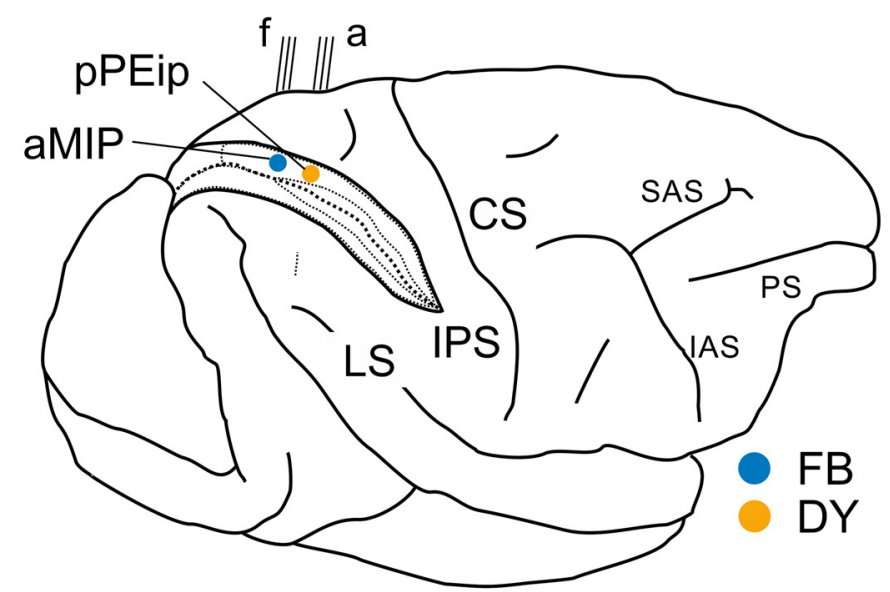

Case 73
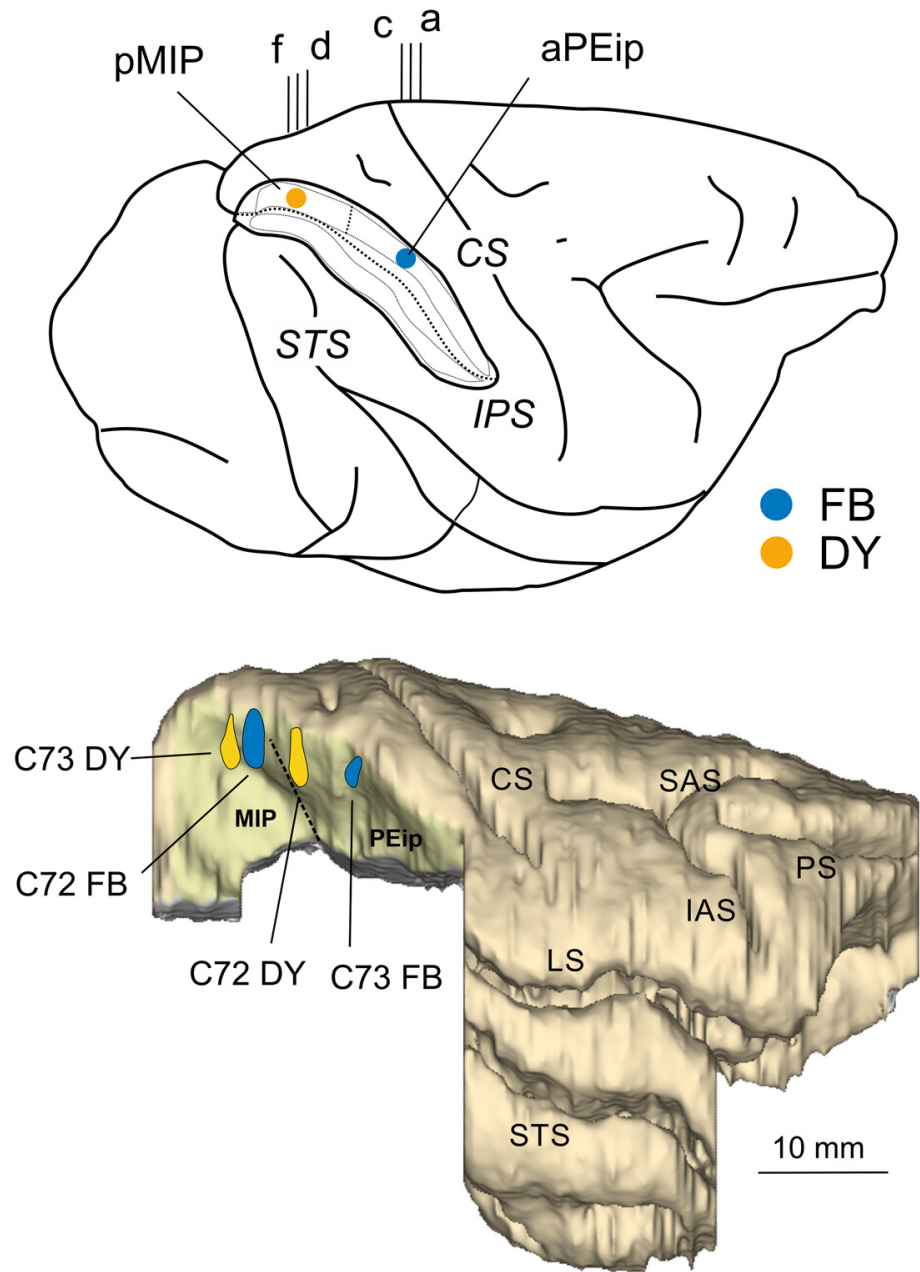
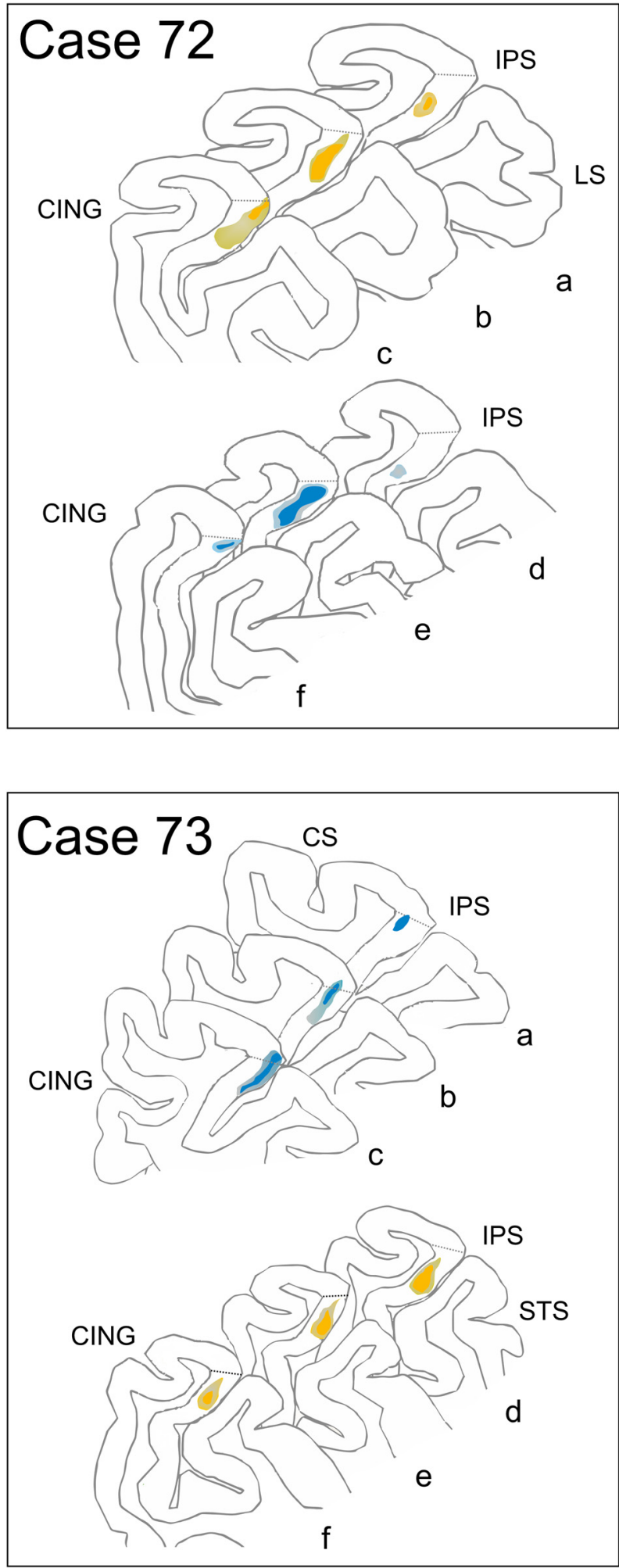

Figure 1. Brain figurines in the top and middle left part of the figure and the corresponding histologic sections on the right show the location of the FB and DY injection sites along the db-IPS (IPS) in cases 72 and 73 . Case 73 is shown as a right hemisphere. The IPS is shown as "opened" to better visualize the dorsal and ventral banks. pPEip and aPEip indicate anterior and posterior part of area PEip, respectively. The same applies to area MIP (aMIP, pMIP). In the section drawings, the injection sites are shown as a deep colored zone corresponding to the core surrounded by a light-colored zone corresponding to the halo. The bottom left part of the figure shows a 3D reconstruction of a right hemisphere in which the inferior parietal lobule (IPL), including the ventral bank of the IPS was removed to show in a single comprehensive image the relative A-P 
continued

locations of the four tracer injections (blue and yellow spots) in the different parts of areas MIP and PEip. CS, STS, LS, PS, SAS/IAS, and CING indicate central, superior temporal, lateral, principal, superior/inferior arcuate, and cingulate sulci.

intravenous lethal injection of sodium thiopental $(200 \mathrm{mg} / \mathrm{kg}$, i.v). They were perfused through the left cardiac ventricle with saline, $4 \%$ paraformaldehyde, and $5 \%$ glycerol in this order. All solutions were prepared in phosphate buffer $0.1 \mathrm{M}$, $\mathrm{pH}$ 7.4. Each brain was then blocked coronally on a stereotaxic apparatus, removed from the skull, photographed, and placed in $10 \%$ buffered glycerol for $3 \mathrm{~d}$ and $20 \%$ buffered glycerol for $4 \mathrm{~d}$. Finally, each brain was cut frozen in coronal sections $60 \mu \mathrm{m}$ thick. In cases 10 and 21, the spinal cord was cut in 60- $\mu \mathrm{m}$-thick coronal sections. In cases 72 and 73 , one series of every fifth section was mounted, air-dried, and quickly cover-slipped for fluorescence microscopy. In cases 10 and 21, one series of every fifth section through the right hemisphere and the brainstem, and every tenth section through the spinal cord was processed for HRP histochemistry using tetramethylbenzidine as chromogen
(Mesulam, 1982). Sections were rinsed in $0.01 \mathrm{M}$ acetate buffer, pH 3.3, and developed at $4^{\circ} \mathrm{C}$ in a solution of $0.09 \%$ sodium nitroferricyanide, $0.005 \%$ tetramethylbenzidine, and $0.006 \%$ hydrogen peroxide in $0.01 \mathrm{~m}$ acetate buffer. Finally, one series of every fifth section in all brains and of every tenth section in the spinal cord in cases 10 and 21, was stained with the Nissl method $(0.1 \%$ thionin in $0.1 \mathrm{~m}$ acetate buffer, pH 3.7).

\section{Injection sites and distribution of retrogradely labeled neurons}

In cases 72 and 73, the FB and DY injection sites, defined according to Kuypers and Huisman (1984) and Condé (1987), were completely restricted to the cortical gray matter, involving almost the entire cortical thickness,
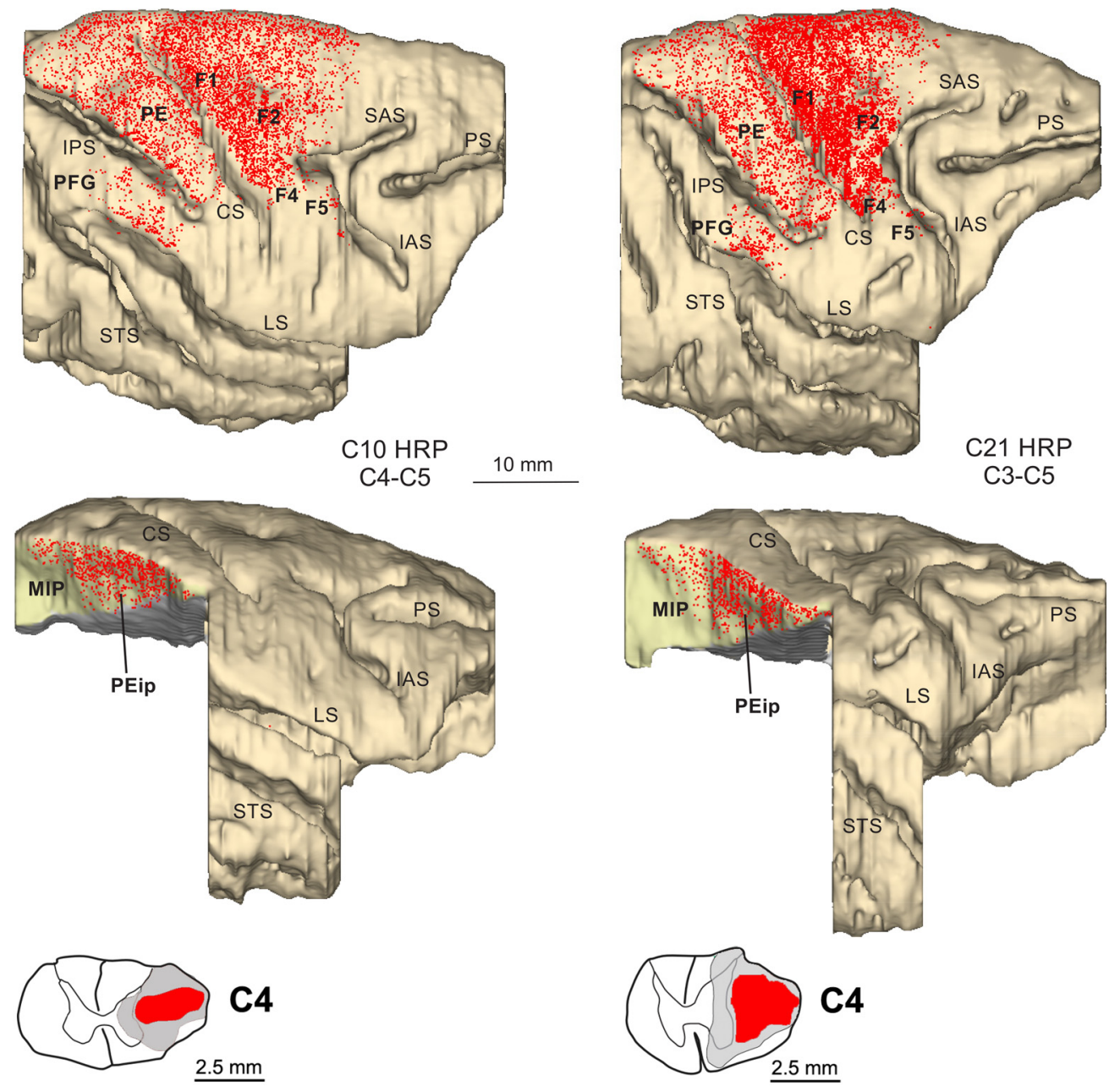

Figure 2. Distribution of retrogradely-labeled cells (RLCs) observed following HRP injections in the lateral funiculus of the spinal cord at upper cervical levels in cases 10 and 21, shown in dorsolateral views of the 3D reconstructions of the injected hemispheres and lateral views of the db-IPS exposed after dissections of the IPL and of part of temporal lobe. Each dot corresponds to one labeled neuron. In the lower part of the figure, coronal sections through C4 level of the spinal cord show the HRP injection core (in red) and halo (in gray). Other abbreviations as in Figure 1. 
Table 1. Percentages (\%) and total number $(n)$ of labeled neurons observed after tracer injections in MIP and PEip

\begin{tabular}{|c|c|c|c|c|}
\hline Injected area & aPEip & pPEip & aMIP & pMIP \\
\hline Case & 73FB & 72DY & $72 \mathrm{FB}$ & 73DY \\
\hline \multicolumn{5}{|l|}{ Prefrontal } \\
\hline 12r, 12l, 12m\&12o, 11m\&11l, 13,GrFO, 10, 31, 32, 24, 25, 14, 9, 45A\&B, 46d, 46v, 8B, 8r\&FEF & - & - & - & - \\
\hline \multicolumn{5}{|l|}{ Frontal } \\
\hline $\begin{array}{l}\text { F6 } \\
\text { F7 } \\
\text { F3 } \\
\text { F2 } \\
\text { F5 } \\
\text { F4 } \\
\text { M1 (F1) } \\
\end{array}$ & $\begin{array}{l}- \\
- \\
1.4 \\
1.2 \\
1.5 \\
5.0 \\
15.6 \\
\end{array}$ & $\begin{array}{l}0.2 \\
0.3 \\
4.9 \\
13.4 \\
0.7 \\
2.9 \\
13.5 \\
\end{array}$ & $\begin{array}{l}- \\
0.1 \\
1.6 \\
10.9 \\
0.2 \\
- \\
3.8 \\
\end{array}$ & $\begin{array}{l}- \\
- \\
1.3 \\
10.2 \\
0.5 \\
0.2 \\
3.7 \\
\end{array}$ \\
\hline \multicolumn{5}{|l|}{ Cingulate } \\
\hline $\begin{array}{l}24 c \& d \\
24 a \& b \\
23 a \& b \\
23 c\end{array}$ & $\begin{array}{l}3.7 \\
- \\
- \\
3.7 \\
\end{array}$ & $\begin{array}{l}3.0 \\
0.2 \\
- \\
1.6 \\
\end{array}$ & $\begin{array}{l}2.7 \\
0.1 \\
- \\
1.2 \\
\end{array}$ & $\begin{array}{l}2.0 \\
0.3 \\
- \\
2.3 \\
\end{array}$ \\
\hline \multicolumn{5}{|l|}{ Somatosensory } \\
\hline $\begin{array}{l}\text { SI } \\
\text { SII } \\
\text { Insular }\end{array}$ & $\begin{array}{l}7.3 \\
1.6 \\
1.7 \\
\end{array}$ & $\begin{array}{l}- \\
0.2 \\
- \\
\end{array}$ & $\begin{array}{l}- \\
- \\
- \\
\end{array}$ & $\begin{array}{l}- \\
- \\
- \\
\end{array}$ \\
\hline \multicolumn{5}{|l|}{ Superior parietal lobule (SPL) } \\
\hline $\begin{array}{l}\text { PE } \\
\text { PEc } \\
\text { PEci } \\
\text { PGm } \\
\text { V6A } \\
\end{array}$ & $\begin{array}{l}18.3 \\
1.1 \\
2.2 \\
- \\
0.7 \\
\end{array}$ & $\begin{array}{l}11.1 \\
4.2 \\
5.3 \\
1.6 \\
10.5 \\
\end{array}$ & $\begin{array}{l}17.8 \\
18.2 \\
6.1 \\
7.1 \\
7.3 \\
\end{array}$ & $\begin{array}{l}4.1 \\
12.5 \\
12.9 \\
0.7 \\
22.2 \\
\end{array}$ \\
\hline \multicolumn{5}{|l|}{ Intraparietal (IPS) } \\
\hline $\begin{array}{l}\text { PEip } \\
\text { MIP } \\
\text { AIP } \\
\text { VIP } \\
\text { LIP } \\
\end{array}$ & $\begin{array}{l}\mathbf{X} \\
5.1 \\
6.3 \\
5.5 \\
- \\
\end{array}$ & $\begin{array}{l}\mathbf{X} \\
12.9 \\
0.5 \\
2 \\
- \\
\end{array}$ & $\begin{array}{l}13.8 \\
\mathbf{X} \\
- \\
0.7 \\
- \\
\end{array}$ & $\begin{array}{l}16.5 \\
\mathbf{X} \\
0.2 \\
1.3 \\
- \\
\end{array}$ \\
\hline \multicolumn{5}{|l|}{ Inferior parietal lobule (IPL) } \\
\hline $\begin{array}{l}\text { PF } \\
\text { PFG } \\
\text { PG } \\
\text { Opt } \\
\text { PGop } \\
\end{array}$ & $\begin{array}{l}0.7 \\
3.8 \\
0.7 \\
- \\
11.7 \\
\end{array}$ & $\begin{array}{l}- \\
2.4 \\
3.4 \\
- \\
4.2 \\
\end{array}$ & $\begin{array}{l}\overline{1} \\
1.1 \\
3.6 \\
- \\
2.8 \\
\end{array}$ & $\begin{array}{l}- \\
0.8 \\
4.3 \\
- \\
3.9 \\
\end{array}$ \\
\hline \multicolumn{5}{|l|}{ Temporal } \\
\hline $\begin{array}{l}\text { MST } \\
\text { MT } \\
\text { Tpt }\end{array}$ & $\begin{array}{l}1 \\
- \\
0.2\end{array}$ & $\begin{array}{l}0.8 \\
- \\
-\end{array}$ & $\begin{array}{l}0.7 \\
- \\
0.1\end{array}$ & $\begin{array}{l}- \\
- \\
-\end{array}$ \\
\hline Total number of labelled cells ( $n$ ) & 20,556 & 62,312 & 21,927 & 61,135 \\
\hline
\end{tabular}

Injection sites are sorted relative to their A-P position along the db-IPS, to better display the gradient-like distribution of their projections $(-$, labeling $<0.1 \%$ or no labeling). No cell counts are reported for the areas containing the injection sites $(X)$.

or at least layers III-V. Injection sites were then attributed to area PEip or MIP, as defined from the distribution of corticospinal labeled neurons in the db-IPS (cases 10 and 21), as detailed in Table 1.

The cortical distribution of FB-retrogradely and DY-retrogradely labeled cells (cases 72 and 73), as well as of HRP-labeled cells (cases 10 and 21), here referred to as retrogradely-labeled cells (RLCs), was plotted in sections every $600 \mu \mathrm{m}$ (300 $\mu \mathrm{m}$ in cases 10 and 21). In each examined section the outer and inner cortical borders and the location of each labeled neuron were plotted with the aid of inductive displacement transducers mounted on the $x$ and $y$-axes of the microscope stage. The transducer signals were digitized and stored by using software developed 
in our laboratory that allows the visualization of section outlines, of gray-white matter borders, and of labeled cells.

Data from individual sections were then imported into the three-dimensional (3D) reconstruction software developed in house (Demelio et al., 2001) to create volumetric reconstructions of the hemispheres from individual histologic sections containing connectional and/or architectonic data and providing realistic visualizations of the labeling distribution. The distribution of RLCs on exposed cortical surfaces was visualized in mesial and dorsolateral views of the hemispheres, whereas that in the db-IPS in lateral views of the hemispheres, in which the bank was exposed with dissection of the inferior parietal lobule (IPL) and the temporal lobe.

The nomenclature and the map adopted for the areal attribution of the labeled neurons was the same of that used in a recent quantitative study of the connectivity of the parieto-frontal system (Caminiti et al., 2017). Briefly, the superior and medial parietal cortex was defined according to architectonic criteria described in Pandya and Seltzer (1982) and Luppino et al. (2005), while area MIP was defined based on the distribution of corticospinal projections (see Results). In the IPL the gyral convexity areas were defined according to cytoarchitectonic and chemoarchitectonic criteria described in Gregoriou et al. (2006) and those of the lateral bank of the intraparietal sulcus based on connectional criteria described in Borra et al. (2008). The fundal region of the intraparietal sulcus was assigned to the ventral intraparietal (VIP) area as defined by Colby and Duhamel (1991). In the frontal lobe, frontal and cingulate motor areas were defined according to architectonic criteria described in Matelli et al. $(1985,1991)$ and Belmalih et al. (2009). Prefrontal areas were defined according to Carmichael and Price (1994), Gerbella et al. (2007), and Saleem et al. (2014).

\section{Quantitative analysis and laminar distribution of retrograde labeling}

In all the cases, we counted the number of RLCs plotted in the ipsilateral hemisphere, beyond the limits of the injected area, in sections at every 600- $\mu \mathrm{m}$ interval. Cortical afferents to areas PEip or MIP were then expressed in terms of the percentage of labeled neurons found in a given cortical subdivision, with respect to the overall retrograde labeling found for each tracer injection. As for the brain parcellation adopted in this study, for both histologic and tractography data, see dedicated paragraph below.

Furthermore, to obtain information about the laminar patterns of the observed connections, the labeling attributed to a given area and reliably observed across different sections and cases was analyzed in sections at every $300 \mu \mathrm{m}$ in terms of amount of RLCs located in the superficial (II-III) versus deep (V-VI) layers.

\section{DW-MRI experiment}

Brain processing for ex vivo DW-MRI acquisition

The DW-MRI data from ex vivo brain of a male Macaca mulatta (M105, fouryears and 10 months old, $10.1 \mathrm{~kg}$ body weight) available from Ambrosen et al. (2020) was used. The brain was perfused following the protocol illustrated in Ahmed et al. (2012) and prepared for MRI ex vivo scanning as described by Dyrby et al. (2011). The DWMRI data were acquired at $0.5 \mathrm{~mm}$ isotropic resolution. The data were sampled in 180 uniformly distributed directions on each of three $b$-value shells $(b=[1.477,4.102$, $8.040] \mathrm{ms} / \mu \mathrm{m}^{2}$ ) and nine non-diffusion-weighted images $\left(\mathrm{b}=0 \mathrm{~ms} / \mu \mathrm{m}^{2}\right)$. The protocol was repeated twice and averaged before further processing (for more details on the MRI acquisition protocol, see Ambrosen et al., 2020). We also used the midcortical surface from Ambrosen et al. (2020). The fiber orientation distributions were estimated using the multi-shell multi-tissue constrained spherical deconvolution algorithm available in the MRtrix3 software (Jeurissen et al., 2014; Tournier et al., 2019). The brain partial volume estimates for the white matter, gray matter, and cerebrospinal fluid were obtained from the averaged non-diffusion-weighted image using the FSL Fast software (Zhang et al., 2001).

\section{Brain parcellation}

We used the brain parcellation of the right hemisphere available in Girard et al. (2020). Fifty-nine cortical areas were manually parcellated following the study by Caminiti et al. (2017), on the animal used for the ex vivo DW-MRI acquisition. Areas $46 \mathrm{dr}$ and $46 \mathrm{dc}$ were grouped in a single ROI, 46d. Similarly, we grouped areas 46vr, r46vc, c46vc in ROI 46v, areas c12r, i12r, r12r in ROI 12r, areas 9l, 9m in ROI 9, areas 45A, 45B in ROI 45, areas 8Ad, $8 \mathrm{Av}$ in ROI 8r\&FEF, areas F7-PMdr, F7-SEF in ROI F7, areas F2vr, $\mathrm{F} 2$ preCD in $\mathrm{ROI} F 2$, areas $\mathrm{F} 5 \mathrm{p}, \mathrm{F} 5 \mathrm{a} / 44, \mathrm{~F} 5 \mathrm{c}$ in $\mathrm{ROI} \mathrm{F} 5$. Areas 24 and 25, the insula and Tpt were added to cortical parcellation based on atlases of the rhesus monkey brain (Paxinos et al., 2009; Saleem and Logothetis, 2012). Together, these cortical areas make 48 ROls for investigating the connectivity of PEip and MIP. To obtain a detailed parcellation of the db-IPS, we first merged area PEip and MIP in a single area. This resulted in 38 A-P MRI coronal slices (from \#105 to \#68; each 0.5-mm thickness) of the bank, which was then divided into three equally wide sectors: dorsal, middle, and ventral. However, the most anterior part of the area PEip was excluded from the fine parcellation of the db-IPS, because of the difficulty in identifying three sectors. The parcellation was done in the native MRI image space. The MRI images were manually aligned to the stereotaxic plane of the histologic sections for visual inspection.

\section{DW-MRI tractography and connectivity}

Probabilistic streamline tractography was performed using the Particle Filtering Tractography algorithms (Girard et al., 2014) available in the DIPY software library (Garyfallidis et al., 2014). Tractography was initiated in all white matter voxels using 25 seeds per voxel $(9,713,750$ seeds). Streamlines with a length superior to $2 \mathrm{~mm}$ in the white matter volume were used as input to the Convex Optimization Modelling for Microstructure Informed Tractography (COMMIT) method (Daducci et al., 2015). COMMIT was used to estimate each streamline contribution (weights) to the intra-axonal MRI signal fraction following the Stick-Zeppelin-Ball white matter microstructure 
model (Panagiotaki et al., 2012; Daducci et al., 2015). The tractography and microstructure estimation was repeated four times, resulting in a total of $23,137,312$ streamlines and weights. All streamlines with an endpoint located in one of the 48 cortical ROls and an endpoint in the A-P coronal slices of the db-IPS were selected for the diffusionbased connectivity analysis. Streamlines were selected using the MRtrix 3 tck2connectome (Tournier et al., 2019) command, identifying connected $\mathrm{RO}$ ls with a radial search of $1 \mathrm{~mm}$ around streamlines endpoints. This resulted in 73,390 streamlines connecting the db-IPS to the cortical areas (dorsal: 29,378; middle: 24,474; ventral: 19,538).

\section{Diffusion-based connectivity estimation}

To cover a similar extent as the tracer injections, we merged the dorsal and middle sectors of our 3-fold subdivision of the db-IPS. We used a sliding window of five MRI coronal slice $(2.5 \mathrm{~mm})$ moving in the A-P direction selecting all streamlines connecting the merged sectors of the window to the cortical ROls. From the 38 coronal MRI slices (\#105 to \#68), we obtained 34 windows in the A-P extent of the db-IPS, with each window made of five consecutive MRI slices (centered at slices \#103 to \#70, the two bordering slices at each extremity of the db-IPS were excluded). For each sliding window and each cortical ROI, we computed the sum of the COMMIT weights (i. e., estimation of the intra-axonal MRI signal fraction) associated with streamlines interconnecting them.

The diffusion-based connectivity distribution of a sliding window (dorsal and middle sectors of the db-IPS of five consecutive coronal MRI slices) was obtained by dividing each ROl's weight by the sum of the weights associated with streamlines connecting that window to all cortical ROIs. The Pearson's correlation coefficient was used to compare the diffusion-based connectivity distribution of each window with the histologic cell count distributions of the four injection sites.

\section{Results}

\section{Neural tracers study \\ Subdivision of the $d b-I P S$ and location of the injection sites}

The location of the injection sites placed at different A-P levels in the $\mathrm{db}$-IPS and involving the bank for several $\mathrm{mm}$ in depth (cases 72 and 73) is shown in Figure 1. To assign injection sites and RLCs in the db-IPS to specific cortical entities, as in Matelli et al. (1998), we subdivided this region based on the distribution of corticospinal neurons, which clearly distinguishes between a rostral and a caudal sector (Fig. 2).

The upper part of Figure 2 shows the overall distribution on the dorsolateral cortical surface of the corticospinal labeled neurons observed after the injection of HRP in the lateral funiculus at the upper cervical levels (cases 10 and 21). The extensive labeling observed in both cases all over the precentral and postcentral gyri, except their most lateral part, suggested complete, or almost complete involvement of the contralateral lateral funiculus by the HRP injection. In the lower part of Figure 2, lateral views of the two hemispheres show the distribution of the RLCs observed in the db-IPS. In both hemispheres, the rostral part of the bank hosted the highest number of them, as compared with its caudal part, from the crown to the fundus. This rostral sector, which does not appear to project to the thoraco-lumbar spinal cord (Matelli et al., 1998) and hosts neurons dysinaptically connected with hand motorneurons (Rathelot et al., 2017), has been here referred to as PEip, according to the original definition of Matelli et al. (1998). Caudal to PEip, corticospinal neurons appeared to be confined to the uppermost part of the bank, which, therefore, for most of its extent lacked these projections. This last sector as a whole has been here referred to as area MIP. The border between PEip and MIP tended to run obliquely, from a ventrorostral to a dorsocaudal position and, at about half of the depth of the bank appeared to be located at an A-P level of $\sim 13 \mathrm{~mm}$ caudal to the rostral tip of the IPS. In the caudalmost part of the bank, MIP borders caudally with V6A (Luppino et al., 2005; Bakola et al., 2017).

\section{Ipsilateral cortical projections to area MIP}

Two tracer injections targeted MIP (Fig. 1), one in case 72 , where DY was placed in aMIP and one in case 73 , where FB was delivered in PMIP. The analysis of the distribution of RLCs in the ipsilateral hemisphere revealed substantial labeling in both frontal and parietal areas with a smaller contribution from selected cingulate zones (Table 1). The results from these two injections will be described together and are illustrated in Figures 3-5.

Projections from frontal and cingulate cortex. In frontal cortex, RLCs were found mostly in a region spanning from the ventrorostral sector of area F2 (F2vr), around the spur of the arcuate sulcus, up to the border with primary motor cortex (M1; F1) in the dorsal part of premotor cortex (Figs. 3, 4:2-4, 5:2-6). In both cases, they represented $\sim 10 \%$ of the total number of RLCs. Labeling extended over the classical arm region described in previous studies that combined anatomic tracing and physiological recording during reaching tasks (Caminiti et al., 1991; Johnson et al., 1996), as well as in the region of the arcuate spur, where neural activity is more related to hand movement (Fogassi et al., 1999). Smaller proportions of RLCs (3.7-3.8\%; Figs. 4: 4-6, 5: 6-11) were found over the arm region of M1 (see Johnson et al., 1996), lateral to the precentral dimple. No RLCs were found in the mesial part of $M 1$, in the leg and foot representations, in line with data showing that neural activity in MIP is mostly related to visuomotor control of coordinated eye-hand actions.

A very small proportion of RLCs was observed in area F3 [supplementary motor area (SMA); 1.3-1.6\%; Fig. 3], and a moderate number of them was located in the agranular cingulate area 24c/d (2-2.7\%; Figs. 4: 4-5, 5: 4-6) and in the granular cingulate area $23 \mathrm{c}(1.2-2.3 \%$; Figs. 4 : 7-8, 5: 7-13).

Projections from parietal cortex. In posterior parietal cortex, RLCs were found in both the SPL and, to a lesser extent, IPL. In SPL, after the aMIP injection, there was 


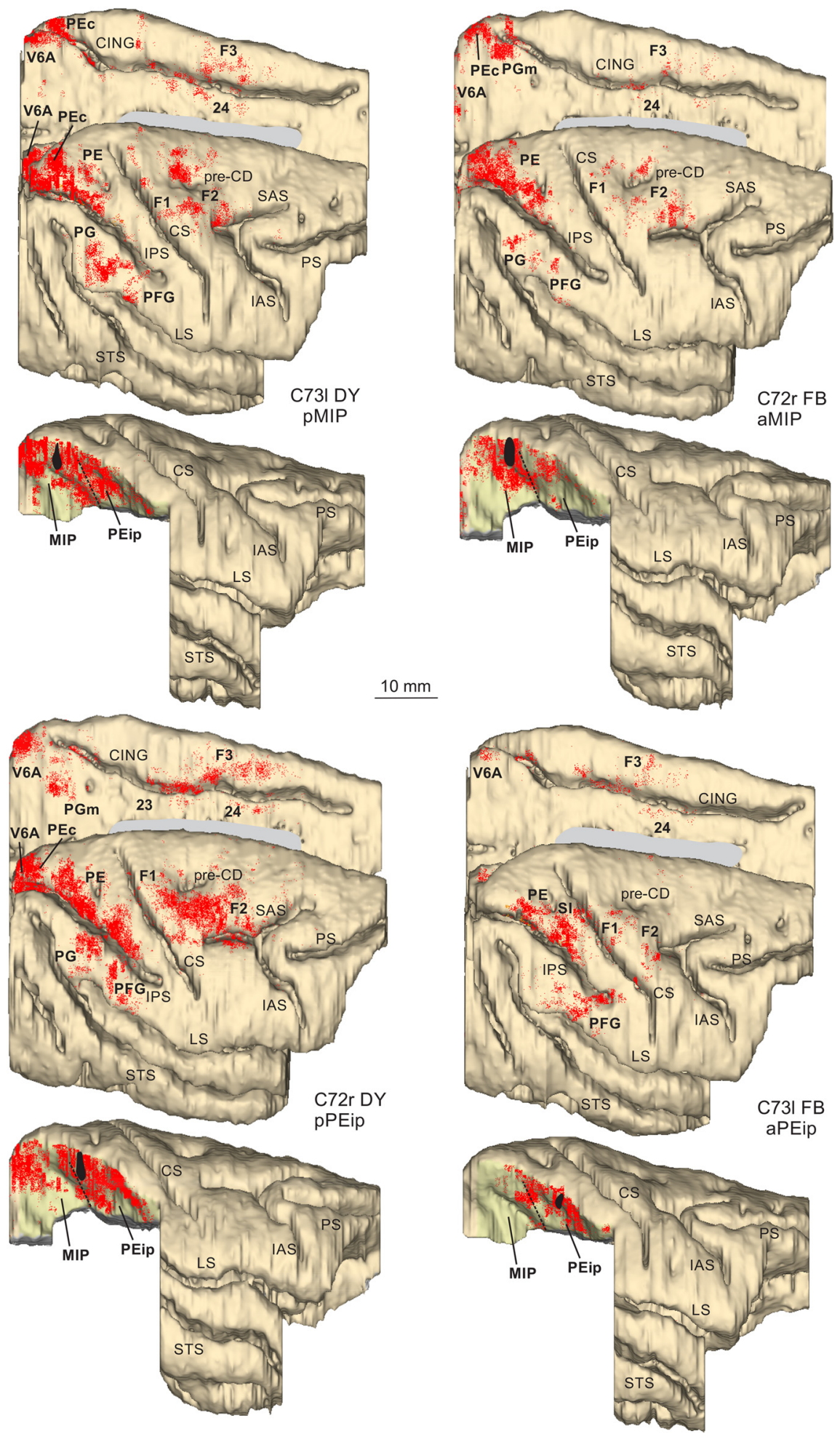

Figure 3. Distribution of RLCs observed following tracer injections in the db-IPS, shown in dorsolateral and mesial views of the injected hemispheres and in lateral views of the db-IPS. The hemisphere of case 73 is shown as a right hemisphere. Abbreviations and conventions as in Figures 1, 2; pre-CD indicates the precentral dimple.

strong labeling in areas PEc (18.2\%; Figs. 3, 4: 14-15), PEip (17.8\%; Figs. 4, 5: 7-13), and PE (13.8\%; Figs. 3, 4: 10-12), After the PMIP injection, the labeling was similarly robust in PEip (16.5\%; Figs. 3, 5: 9-13), weaker but still strong in PEc (12.5\%; Figs. 3, 5: 3-16), modest in PE (4.1\%).

On the medial wall of the SPL, projections from area PEci were stronger to pMIP (12.9\%) than to aMIP (6.1\%; 


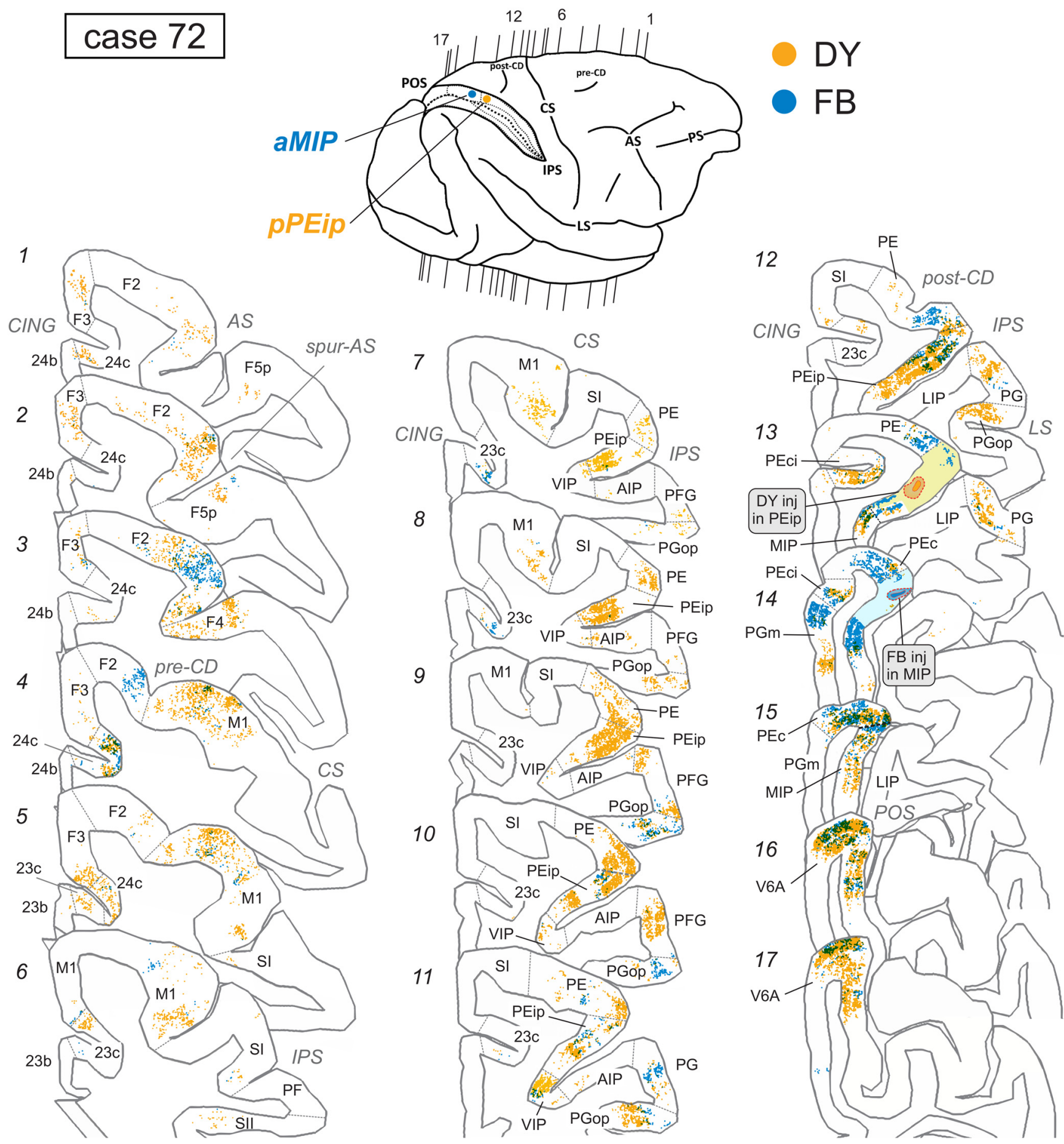

Figure 4. Distribution of retrogradely FB-labeled (blue) and DY-labeled cells (yellow) observed in case 72 after the tracer injections in aMIP and pPEip, respectively, shown in representative sections through the frontal and the parietal cortex. The lightly colored zone surrounding the injection site in sections 13 and 14 corresponds to a sector with homogeneous intrinsic labeling. The levels at which the sections were taken is indicated in the drawing of the hemisphere in the upper part of the figure. POS, parieto-occipital sulcus; post-CD indicates postcentral dimple. Other abbreviations as in Figures 1, 2.

Figs. 3, 4: 13-14, 5: 14-16) and those from PGm were mostly addressed to aMIP (7.1\%; Figs. 3, 4: 14). Finally, projections from area V6A were mostly $(22.2 \%)$ addressed to pMIP (Fig. 5: 17-19), but in smaller proportion also to aMIP (7.3\%: Fig. 4: 16-17).
The only IPL areas projecting to MIP, although with a relatively modest proportion of cells $(4.3 \%$ to pMIP; $3.65 \%$ to aMIP), were areas PG (Figs. 3, 4: 11-13, 5: 13) and PGop (Figs. 4: 7-12, 5: 8-13). RLCs were sparse in VIP (Fig. 4: 7-11), virtually absent in AIP, absent in LIP. 


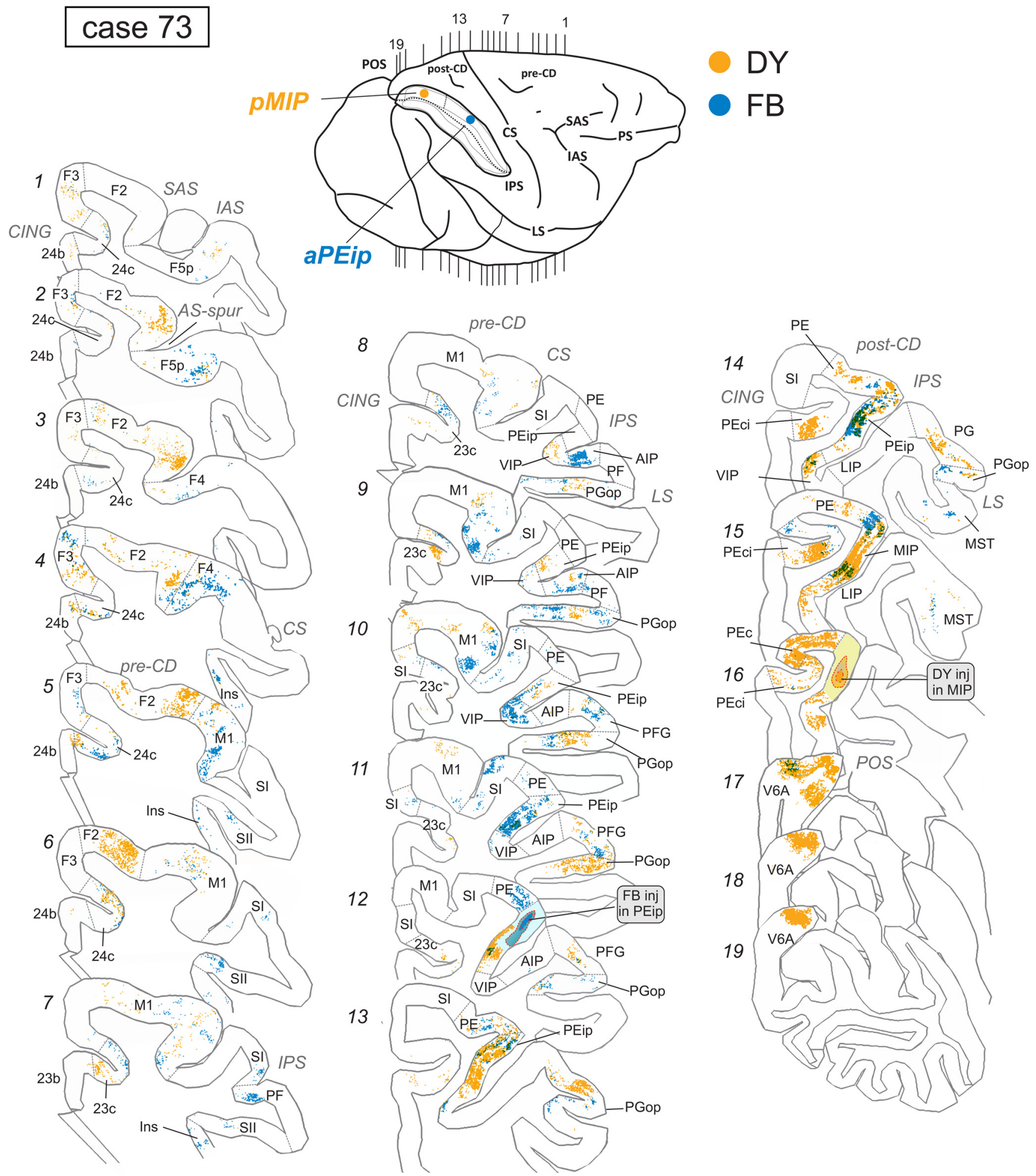

Figure 5. Distribution of retrogradely FB-labeled (blue) and DY-labeled cells (yellow) observed in case 73 after the tracer injections in aPEip and pMIP, respectively, shown in relevant sections through the frontal and the parietal cortex. Conventions and abbreviations as in Figures 1, 2, 4.

Area MST contained a very small proportion $(0.7 \%)$ of cells projecting to aMIP. Finally, very few RLCs were observed in SI and SII. No RLCs projection to MIP were found in prefrontal areas.
Ipsilateral cortical projections to area PEip

Two tracer injections targeted PEip (Fig. 1), one in case 73 , where FB was placed at about its middle part, and one in case 72 , where DY was placed in the caudalmost 


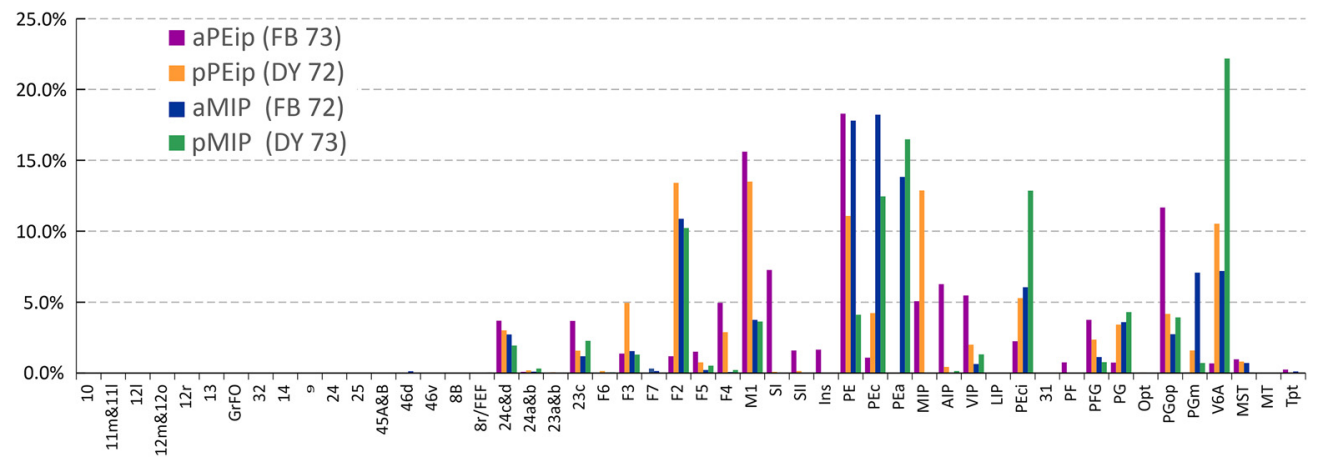

Figure 6. Ipsilateral cortical projections to areas aPEip, pPEip, aMIP, and pMIP. Proportion of cells projecting from different areas to the four injection sites located in area aPEip (purple), pPEip (orange), aMIP (blue), pMIP (green). MIP cells projecting to PEip, and vice versa, are included. Percentages are calculated relative to the total counts of RLCs obtained after each injection.

part of it, adjoining the border with MIP (pPEip). As observed after the tracer injections in MIP, RLCs substantially involved frontal and parietal areas, and their distribution reflected A-P gradients of connectivity in the db-IPS.

Projections from frontal and cingulate cortex. As shown in Table 1, after both the aPEip and the pPEip injections robust labeling was found in $\mathrm{M} 1 \mathrm{15.6 \%}$ and $13.5 \%$, respectively). Robust connectivity with $\mathrm{M} 1$, therefore, appears to be a unifying connectional feature of PEip, together with the projection to the spinal cord. In M1, the labeling was mostly located in the medial bank of the CS, thus involving the "new" M1 (Rathelot and Strick, 2009), where hand movements are represented (Figs. 4: 5-8, 5: 5-10). After the pPEip injection, RLCs also extended more rostrally in M1 over the cortex of the precentral convexity, lateral to the precentral dimple (pre-CD; Figs. 3, 4: 4-6). Furthermore, after pPEip, but not aPEip injection, robust labeling was found in F2 (Figs. 3, 4: 1-5). After the pPEip injection, the proportion of RLCs in F2 (13.4\%) was similar to that observed after that in aMIP (10.9\%). However, RLCs were almost completely located lateral to the pre$C D$, whereas after the MIP injection they extended also more dorsally (Fig. 3 ). In both cases, moderate labeling also involved the ventral premotor area F4 (Figs. 3, 4: 3, 5: 3-4) and weaker labeling was observed in F3 (Figs. 3, 4: 1-3, 5: 4-5). Moderate labeling was observed in areas 24c/d and 23c (Figs. 3, 4: 1-7, 5: 1-8).

Projections from parietal cortex. In the SPL, robust labeling to both aPEip and pPEip was observed in area PE, and it was richer after the aPEip injections $(18.3 \%$ vs $11.1 \%)$. In this area, RLCs very densely packed in the rostral part, however after the pPEip injection they also extended in the caudal part, which was the PE sector densely labeled after the MIP injections (Figs. 3, 4: 7-12, 5: 11-15). Caudal to PE, after the pPEip injections, labeling was relatively moderate in PEc (4.2\%) and PEci (5.3\%), weak in PGm (1.6\%), and robust in V6A (10.5\%; Figs. 3, 4: 13-17). In all these areas, labeling was much weaker, or even absent after the aPEip injection (Figs. 3, 5: 14-19). Similarly, the number of RLCs observed in MIP was much higher after the pPEip (12.9\%) than the aPEip (5.1\%) injection .

In the IPL, both aPEip and pPEip were moderately connected with the hand-related area PFG, though after the pPEip injection the labeling moderately involved also PG (Figs. 3, 4: 7-13, 5: 5-7). Furthermore, aPEip was characterized by a robust input from PGop (11.7\%; Fig. 4: 8-10), which was much weaker for pPEip (4.2\%), as well as by relatively robust input from the hand-related area AIP (6.3\%) and in VIP (5.5\%), where RLCs were relatively sparse after the pPEip injections (Figs. 3, 4: 8-12, 5: 8-14).

After the aPEip injection there was robust labeling in SI (7.3\%; Figs. 3, 5: 6-7) and a relatively weak labeling in SII and the insular cortex, all virtually devoid of labeling after the pPEip injection. Finally, a weak input from MST was observed in both cases.

\section{Connectivity profiles of aPEip, pPEip, aMIP, and pMIP}

To offer a quantitative view of the results, the data reported in Figures 4, 5 and in Table 1 were expressed in the form of frequency distribution. Figure 6 reports the proportion of RLCs ( $y$-axis) across cortical areas, which are arranged from left to right ( $x$-axis) according to their approximate A-P location in the cortex.

The frontal input to parietal areas injected in this study stems mostly from areas F2 and M1. Projections from F2 are mainly addressed to pPEip, aMIP, and pMIP, in decreasing order of magnitude. Motor cortex projections follow a similar pattern but differ for a strong input to aPEip as well. Area SI projects only to aPEip. Smaller projections stem from cingulate areas $24 \mathrm{c}$ and 23 and from ventral premotor area F4.

The parietal projections to PEip and MIP are by far stronger that the frontal ones and originate mainly from superior parietal areas, such as PE, PEc, from local connections within PEip and MIP and from V6A, PEci, and $P G m$. Inferior parietal projections are by far weaker, and originate from $P G o p$, especially after the injection in aPEip, with smaller contribution from areas PG and PFG. Finally, aPEip showed a relatively robust connection with AIP and VIP.

In several instances, the projections addressed to PEip and MIP from cingulate, frontal and parietal areas followed a gradient-like pattern, as also shown in Figure 7. Examples are the projections from 24c, M1, and PFG, which all project with decreasing strength to aPEip, pPEip, aMIP, and pMIP. The F2 projections to dorsal 


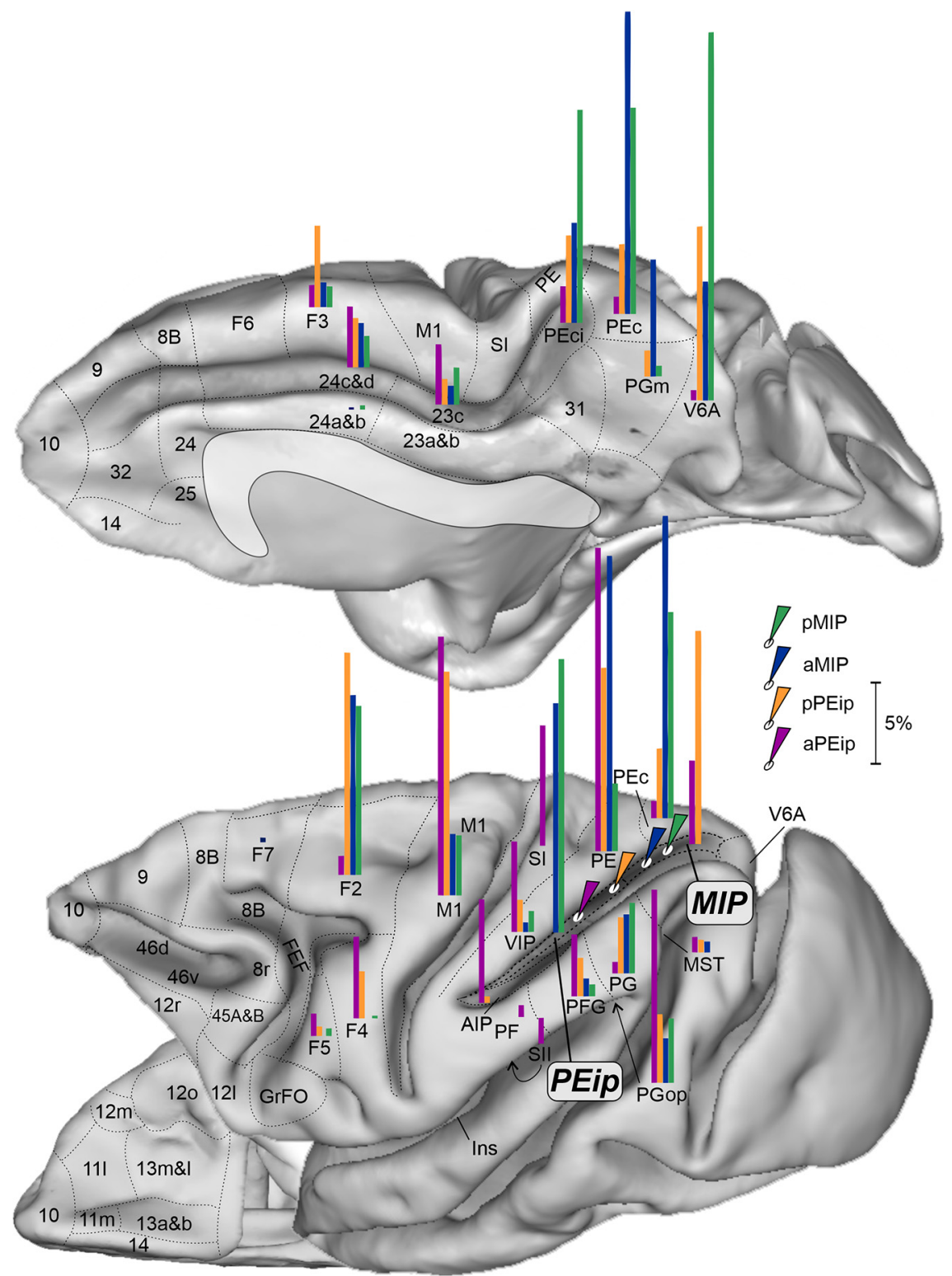

Figure 7. Gradient-like organization of the parietal and frontal projections to the db-IPS. Mesial (top), lateral (bottom, right), and ventral (bottom, left) views of the monkey brain showing the proportion of projecting cells (Fig. 6) in their relative anatomic location, after tracer injections (white ovals with colored arrows) at the four A-P levels of the db-IPS. Each bar has a length proportional to the percent of RLCs (range 1-30\%, scale bar corresponding to 5\%) to aPEip (purple), pPEip (orange), aMIP (blue), and pMIP (green). Conventions as in previous figures.

intraparietal areas display a similar pattern, if one excludes the scant input to aPEip. On the contrary, the strength of PEci projections shows an inverse gradient. The strength of the projections from PE and V6A waxes and wanes in the A-P extent.

A pictorial representation of the gradient-like organization of this part of the parieto-frontal system can be seen in the brain figurine of Figure 7.

\section{Segregation and overlap and laminar distribution of frontal} and parietal cells projecting to PEip and MIP

In the tangential domain of the cortex there exists an orderly arrangement of properties that can relate to the representation of sensory receptors, motor output, visual attention, motor intention, working memory, etc. Moreover, there is evidence that cortical connections shape, at least in part, the functional properties of neurons in the parieto-frontal system (Johnson et al., 1996; Chafee and Goldman-Rakic, 1998, 2000; Battaglia-Mayer et al., 2001).

To study whether PEip and MIP share cortical afferents, therefore functional properties, we compared the tangential distribution of frontal and parietal cells projecting to their anterior and posterior sectors, a study made possible by the injections of two different fluorescent tracers in each of the two animals. 
In case 72, where DY was injected in pPEip and FB in aMIP, frontal cells projecting mostly to pPEip (Fig. 4, see yellow labeling) involve both dorsal premotor area F2 and M1 while those projecting to aMIP (Fig. 4, see blue labeling) occupy restricted frontal zones, mainly located in F2. With the exclusion of a restricted part of the latter (Fig. 4: 2-3), cell projecting to pPEip and aMIP were largely segregated in the tangential domain of the cortex. At some locations, parietal cells projecting to both pPEip and aMIP were segregated (Fig. 4: 7-17), even in the same area, as for PGm (Fig. 4: 14). On the contrary, extensive overlap was found in areas PEc, PEci, and V6A (Fig. 4: 14-17).

The distribution of cells projecting to aPEip and pMIP, where FB and DY were, respectively, injected (Fig. 5) obeys to a similar pattern, where segregation dominates over overlap in both frontal and parietal projections, although some overlap was observed in areas PGop (Fig. 5: 10-11), pPEip (Fig. 5: 13-15), aMIP (Fig. 5: 15), and V6a (Fig. 5, 17).

When comparing the distribution of cells in the rostral bank of the CS, i.e., in the new M1 (Rathelot and Strick, 2009), in both cases 72 and 73 , we mostly observed absence of overlap of cells projecting to the intraparietal areas injected, as well as in area PE and in large part of aPEip, while a small overlap was confined only to very limited zones of the bank (Fig. 5: 6-7).

Finally, the analysis of the laminar distribution of RLCs in the various frontal and parietal areas more densely labeled after the injections in different sectors of PEip and MIP showed a proportion of RLCs in the superficial versus deep layers virtually everywhere within $33 \%$ and $66 \%$, that is a marked bilaminar distribution.

\section{DW-MRI study of the db-IPS}

Comparison between the distribution of RLCs and the diffusion-based connectivity estimates

We compared the connectivity of the 48 cortical regions obtained through histologic procedures with the intraaxonal MRI signal fraction estimated from DW-MRI. This was achieved by computing the Pearson's correlation coefficient between the distribution of RLCs obtained for the four injection sites and the distribution of diffusion-based connectivity estimated at different locations along the entire extent of the db-IPS (see Materials and Methods). To cover in a continuous fashion the whole IPS, we used a sliding window of $2.5 \mathrm{~mm}$, corresponding to five MRI coronal slices, moving in the A-P direction and selecting all streamlines connecting the MRI slices to the 48 cortical ROIs included in our analysis (see Materials and Methods). To better reproduce the extent of the injection sites of retrograde tracers in the $\mathrm{D}-\mathrm{V}$ dimension, the MRI slices encompassed only the dorsal and middle sectors of our 3-fold subdivision of the db-IPS (Fig. 8B). This choice was dictated by the histologic verification that the tracer injections did not involve the deepest part of the dorsal bank, as well as by the fact that the latter can hardly be parcellated into three D-V section in its most anterior part, given the limited extent of the cortex in this dimension.

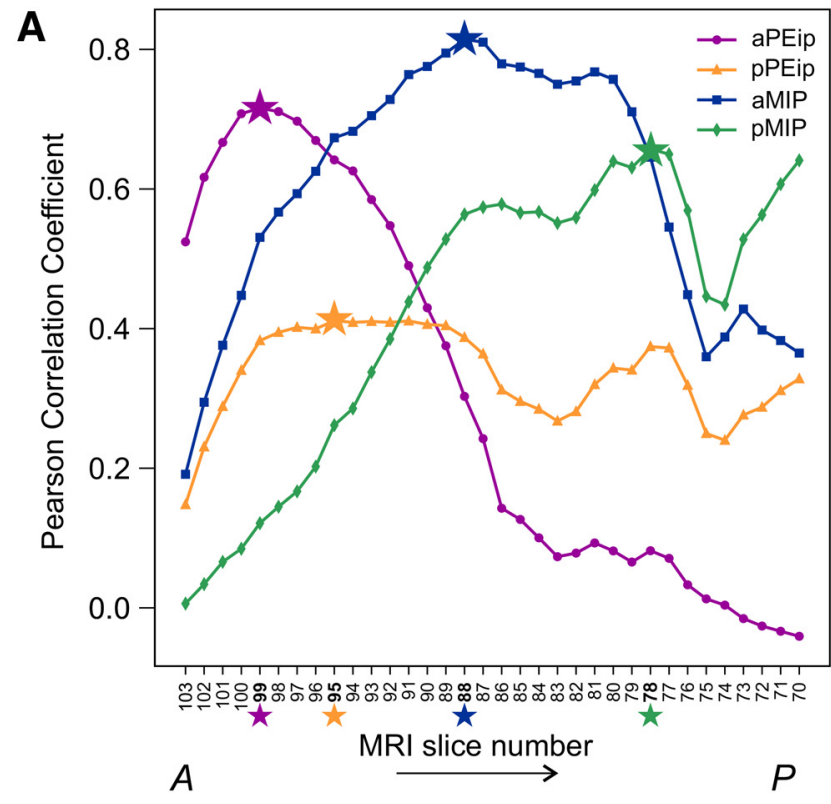

B

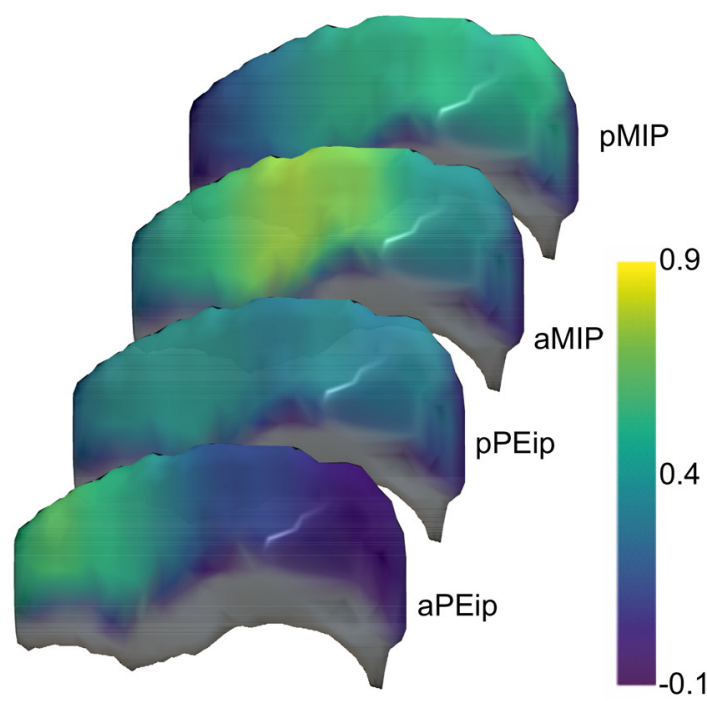

Figure 8. A, Pearson's correlation coefficient between the distribution of diffusion-based connectivity estimated in $2.5-\mathrm{mm}$ windows along the dorsal and middle sectors of the db-IPS and the distribution of labeled cells after the four injections in aPEip, pPEip, aMIP, and pMIP. MRI slice numbers refer to the central position of each sliding window, where slice 103 is the anteriormost and slice 70 the posteriormost. The star markers indicate the A-P location with the highest correlation coefficients. $\boldsymbol{B}$, The Pearson's correlation coefficients after each of the four injections are also reported in color code (see bar on the right) across the db-IPS. In this image, the rostralmost part of the $\mathrm{db}$ IPS is not shown, since given its limited D-V extent, it could not be divided into three sectors.

In Figure $8 A$, data points in each curve show the Pearson's coefficients for the correlation between the distribution of RLCs obtained for each of the injection sites (aPEip, pPEip, aMIP, pMIP) and the diffusion-based connectivity of each $2.5-\mathrm{mm}$ sliding window along the A-P dimension of the db-IPS. The $x$-axis shows the MRI coronal 
slice number at the center of each window. The locations with the highest correlation are indicated by the star markers. The MRI coronal slice number corresponding to each injection site's highest correlation coefficient (Fig. $8 A$, star markers) well agrees with the relative position of the injection sites of neural tracer (Fig. 1). Despite known limitations of DW-MRI connectivity analysis, such as the presence of false-positive connections, Figure $8 A$ shows that tractography can indeed identify changes in the connectivity distribution in the A-P dimension of the db-IPS that are correlated with changes observed using RLCs analysis. In fact, the RLCs distribution after injection in aPEip had the highest correlation value $(r=0.72, n=34$, $p=1.1 \times 10^{-8}$ ) at slice 99, after injection in pPEip at slice $95(r=041, n=48, p=0.004)$, showing however similar correlation values (plateau) at different A-P locations ranging from slices 97 to 89 , while after injection in aMIP the correlation peaked at slice $88(r=0.81, n=34$, $p=1.9 \times 10^{-12}$ ) and after injection in pMIP at slice 78 $\left(r=0.66, n=34, p=3.9 \times 10^{-7}\right)$. This highlights the sensitivity of the DW-MRI connectivity to the changes measured by the RLCs analysis in the fine parcellation of the db-IPS.

When selecting the locations with highest correlation for each of the four injection sites, the overall correlation between the diffusion-based connectivity estimation and the RLCs distribution was $r=0.65(n=192, p=1.7 \times$ $\left.10^{-24}\right)$.

The changes of the correlation coefficient between the distributions of labeled cells and diffusion connectivity across the $\mathrm{db}-\mathrm{IPS}$ are shown in Figure $8 B$, by using a diffusion MRI derived anatomic rendering of the overall the bank to facilitate the comprehension of the areas involved in this analysis. It can be seen that the highest correlation was found in a region spanning the central part (in A-P dimension) and dorso/middle sectors (in D-V dimension) of the bank, after injections in aMIP. A good correlation was also found in the anterior third of the bank after injections in aPEip, while the correlation decreased, although to a different extent, after injections in pPEip and pMIP. The implication of these results for the gradients in the connectivity profiles of the dorsal intraparietal areas will be dealt with in the Discussion. The corresponding distribution of RLCs for the four injection sites alongside the diffusion-based connectivity for the locations with the maximum Pearson's coefficients are reported in Figure 9, together with the relative MRI slices and drawing of the histologic sections.

For the four injections sites there are 192 (48 areas $\times$ four injections) potential ROls connections, among which 113 have non-zero labeled cell counts. Diffusion tractography shows an average of $90.4 \%$ of the connection's weights for ROls with non-zero reported labeled cells. Moreover, tractography correctly identified 107 connections (true-positive connections; TP), thus missing only five connections (false-negative connection; FN). Tractography correctly reported no connectivity for 44 ROIs (true negative connections; TN), but estimated connectivity for 36 ROls where no labeled cells were found (false positive connections; FP).
The overall data analysis resulted in a sensitivity of 0.96 $\left(\frac{T P}{T P+F N}\right)$ and a specificity of $0.55\left(\frac{T N}{T N+F P}\right)$.

Across the matching locations and all cortical ROls, the connection with the most underestimated fraction of diffusion-based connectivity $(-0.143)$ is ROI F2, after injection site in aMIP. This is followed by connection F1-aMIP (-0.135), F1-pMIP (-0.126), F2-aPEip $(-0.111)$, and F2pPEip (-0.109). Similarly, the most overestimated connectivity is PGm-aPEip $(+0.173)$, followed by PE-aMIP (+0.151), PE-pMIP (+0.109), SI-aMIP (+0.103), and VIPaMIP $(+0.096)$. Across the four matching site's location, tractography misestimated the connectivity the most on ROIs F2, PE, M1, VIP and LIP. As examples, contrary to tracer data, our tractography estimations showed streamlines connecting both sectors of PEip (Fig. 9A,B) and MIP (Fig. $9 C, D$ ) to LIP. However, previous histologic studies had shown connections between LIP and MIP (Bakola et al., 2017) and LIP and PEip (referred to as PEa; Blatt et al., 1990). Furthermore, our study shows connections between aPEip and SI (Fig. 9A) which are stronger from tractography than histology. It also reveals streamlines between SI and pPEip (Fig. 9B) and both sectors of MIP (Fig. 9C,D), which are not matched by histology (see also Table 1). Finally, cell counts show strong connectivity between F2 and pPEip (Fig. 9B), as well as with and both sectors of MIP (Fig. 9C,D), which is not matched by tractography.

\section{Diffusion-based connectivity profiles along the db-IPS}

As a next step, we evaluated in a quantitative fashion the degree of similarity of the diffusion-based connectivity estimation along the db-IPS. Figure 10A shows the Pearson's correlation coefficient between the distributions of diffusionbased connectivity estimated in different sliding windows along the A-P extent of the db-IPS. The $x$ - and $y$-axes show the MRI coronal slice number corresponding to the center of each window. A strong correlation is expected between locations distant four or less MRI slices apart, because of the windows overlap. A decrease in correlation can be observed when the distance between windows increases in the A-P extent of the bank. This suggests a general gradient-like organization, where the pattern of cortical connectivity gradually changes. Visual inspection of the correlation matrix highlights the existence of three potential clusters, located anteriorly, centrally, and posteriorly along the bank, that can be identified by their highest correlations (range 1-0.6) between neighboring locations. This suggests that along the A$P$ extent of the $\mathrm{db}$-IPS there might exist three broad hodologically different regions. A similar matrix (Fig. 10B) is shown for selected locations corresponding to the four MRI windows with the highest correlation between the diffusion-based and tract tracing connectivity (see also Fig. 8). It can be seen that similar results were obtained when correlating the pattern of connectivity obtained from histologic tracing data, after injections in intraparietal areas aPEip, pPEip, aMIP, and pMIP.

$D W-M R I$ connectivity estimates of the dorsal, middle, and ventral sectors of the $d b-I P S$

Furthermore, we investigated the cortical connectivity of the dorsal, middle and ventral sectors of the db-IPS 
A
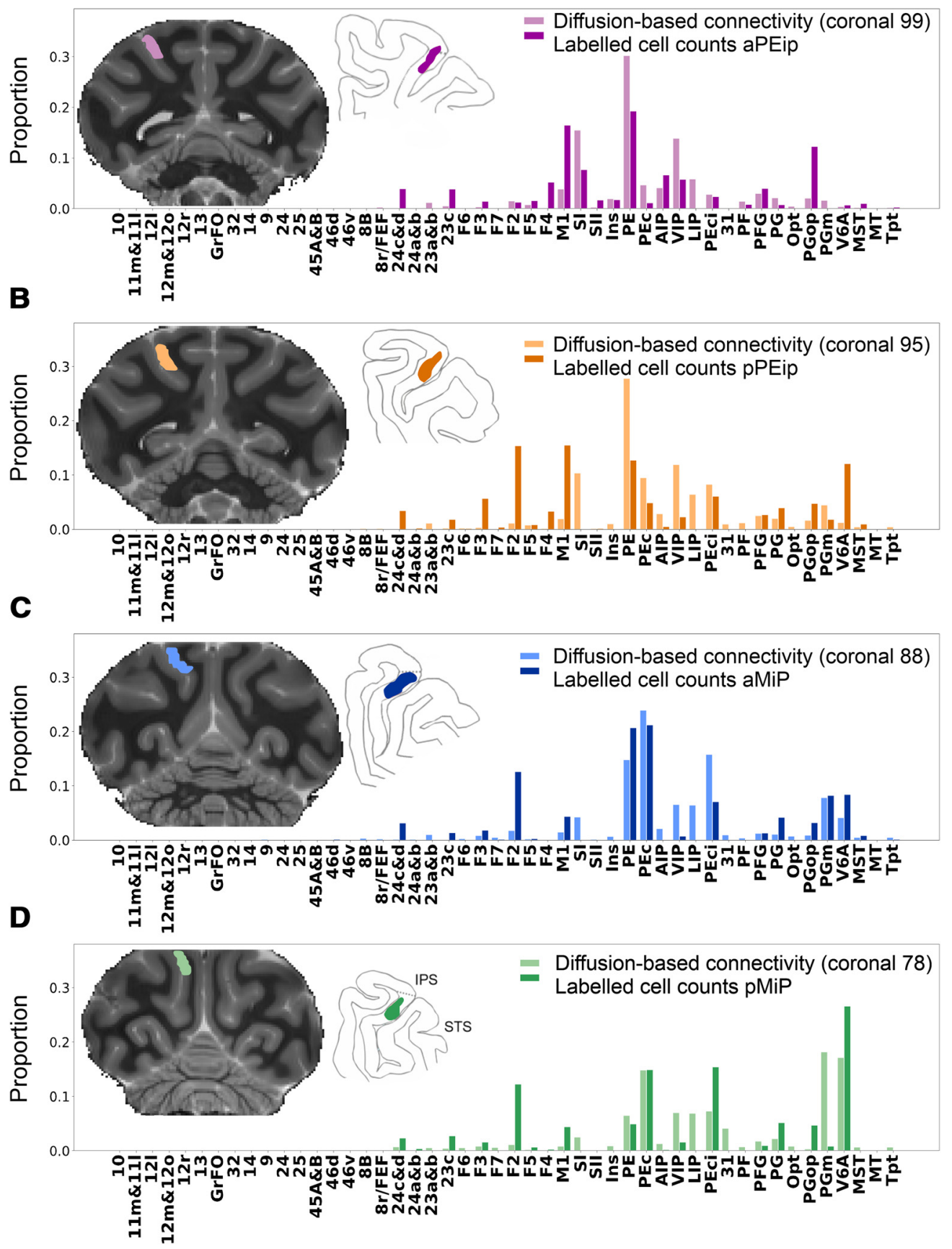

Figure 9. Distribution of labeled cells and diffusion-based connectivity for locations with maximum Pearson's correlation coefficients $(\boldsymbol{A}$, aPEip: $r=0.72 ; \boldsymbol{B}$, pPEip: $r=0.41 ; \boldsymbol{C}$, aMIP: $r=081 ; \boldsymbol{D}$, pMIP: $r=0.66)$. For each distribution, the MRI slices corresponding to the center positions of the sliding windows with highest Pearson's correlation coefficients are reported next to the reconstruction of the histologic sections where the injection sites were found. The local connections between MIP and PEip are not reported.

using diffusion MRI. It is worth stressing, the cortical regions lying in the more ventral and deep part of the bank can be hardly accessed by neural tracer injections, therefore their connectivity remains virtually unknown. The sum of the diffusion-based connectivity calculated across the 38 different A-P locations (MRI slices) for the dorsal, middle and ventral sectors is shown in Figure 11. The parietal areas VIP, V6A, PE, LIP, PEc, PGm, and SI are the ROls showing the overall strongest connectivity with the bank, among the 48 ROIs considered in this study. However, clear differences emerge in the streamline contribution provided by specific portions of the IPS along the D-V dimension.

To highlight this aspect, we report the results (Fig. 12) referring to the connectivity occurring between each of the 12 most connected cortical areas (i.e., VIP, V6A, PE, LIP, PEc, PGm, SI, PEci, AIP, PFG, PG, M1; 


\section{A \\ Correlation between the distributions of the diffusion-based connectivity at different sites of the db-IPS}
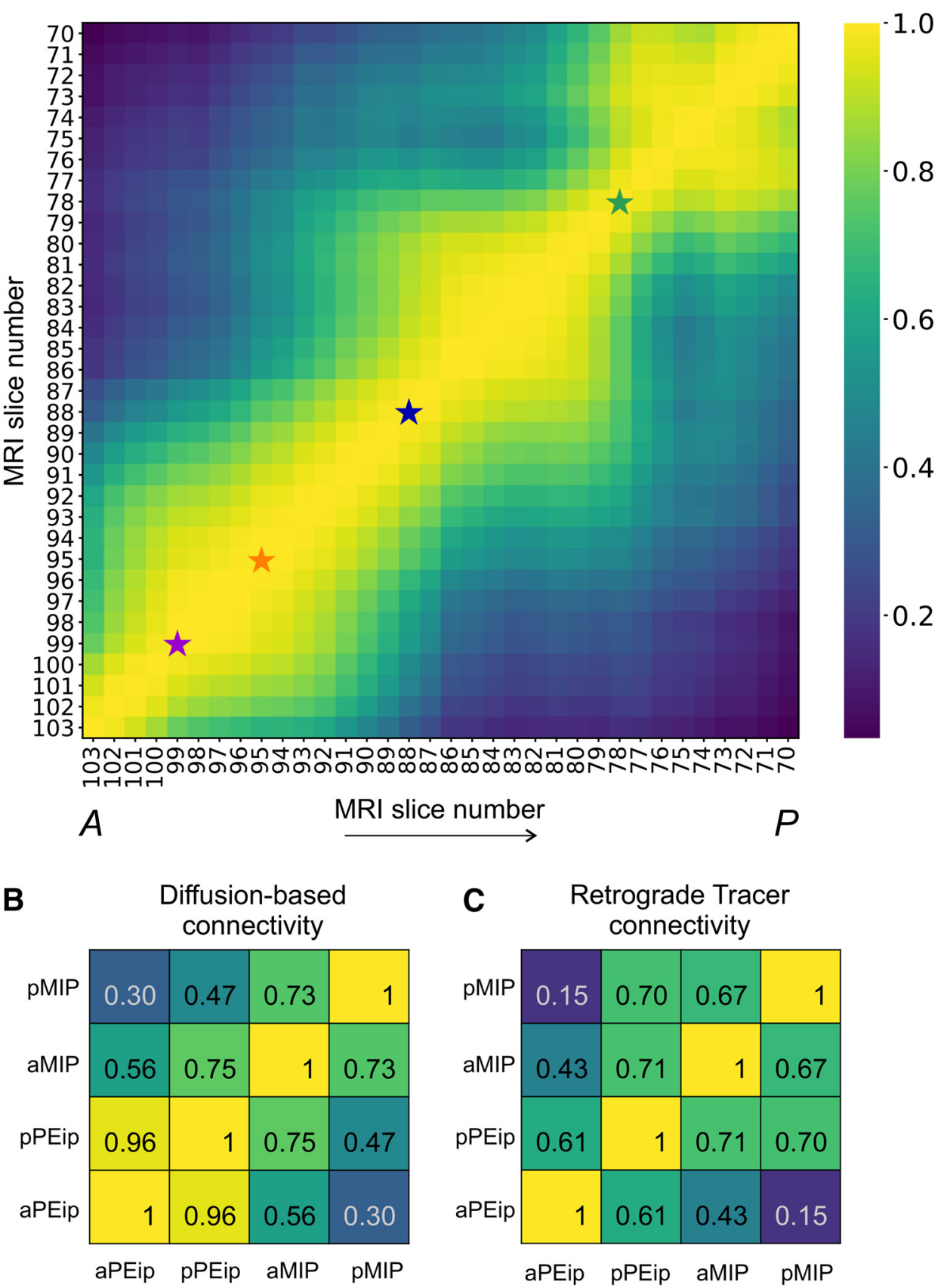

Figure 10. A, Pearson's correlation coefficient between the distributions of the diffusion-based connectivity estimated in subregions along the db-IPS, as defined by a sliding window of $2.5 \mathrm{~mm}$ moving in the A-P direction (five MRI coronal slices). For each window, the connectivity is evaluated first by selecting all the streamlines connecting the MRI slices to the 48 ROIs included in the analysis and summing the contribution to the intra-axonal MRI signal fraction of each streamline for each cortical area. Data were normalized relative to the total contribution of the streamlines associated to each sliding window. The $x$ - and $y$-axes show the MRI slice number corresponding to center position of each window. Star markers (slices 99, 95, 88, and 78) indicate the locations with highest correlation coefficient between diffusion-based connectivity and labeled cells, after tracer injections in aPEip, pPEip, aMIP, and pMIP (Fig. 8). Values of correlation coefficients are indicated by the color code (see bar on the right). B, Pearson's correlation coefficients between the distributions of diffusion-based connectivity estimated at the four sites reported above. C. Pearson's correlation coefficients between the distributions of RLCs after injection in aPEip, pPEip, aMIP, and pMIP. In $\boldsymbol{B}, \boldsymbol{C}$ correlation coefficients are also reported with relative values (color code as in $\boldsymbol{A}$ ). 


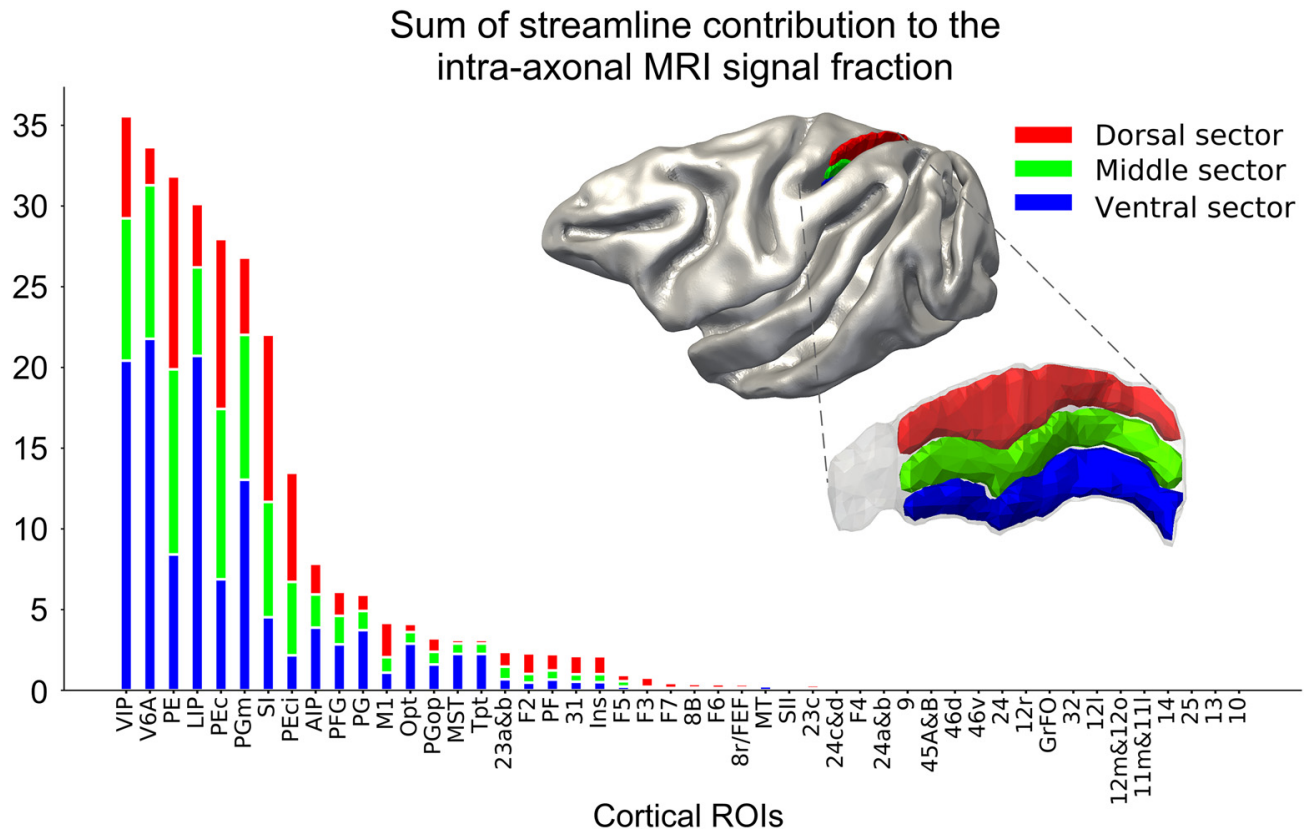

Figure 11. Sum of the cortical connectivity of the db-IPS to other cortical ROIs. For each ROI, the diffusion-based connectivity estimation is reported for the dorsal (red), middle (green), and ventral (blue) sectors. The diffusion connectivity corresponds to the sum of streamline contributions to the intra-axonal MRI signal fraction estimated using COMMIT for each cortical ROI. The sectors of the $\mathrm{db}$-IPS are shown on the mid cortical surface (top right) and on the db-IPS (bottom right). Notice that the rostralmost part of the dbIPS (gray region) was not used for this analysis, since it could not be parcellated intro three D-V sectors, given its limited extent in the D-V dimension).

see Fig. 11), and the A-P and D-V extent of the db-IPS. Each image shows the spatial distribution of the diffusion-based connectivity, along the 38 A-P dorsal, middle and ventral subdivisions of the bank, for each of the 12 cortical ROls listed above. The sectors displaying strong connectivity with the indicated cortical ROI are shown in yellow and orange. It can be seen that there exists a smooth transition in the strength of connectivity in both the A-P and D-V dimensions of the bank. The IPS region more strongly connected with area VIP is the most anterior sector of the bank, with a gradual reduction moving posteriorly, while for V6A is the posteroventral part of the bank, as also observed from tract tracing data on the proportion of RLCs (Fig. 7). Area PE instead display a more diffuse pattern of connectivity along the $\mathrm{D}-\mathrm{V}$ dimension of the anterior part of the bank. LIP connectivity occurs exclusively with the regions located in the more ventral part of the dorsal bank, close to the fundus of the IPS. Another example of a gradient-like distribution of connectivity,
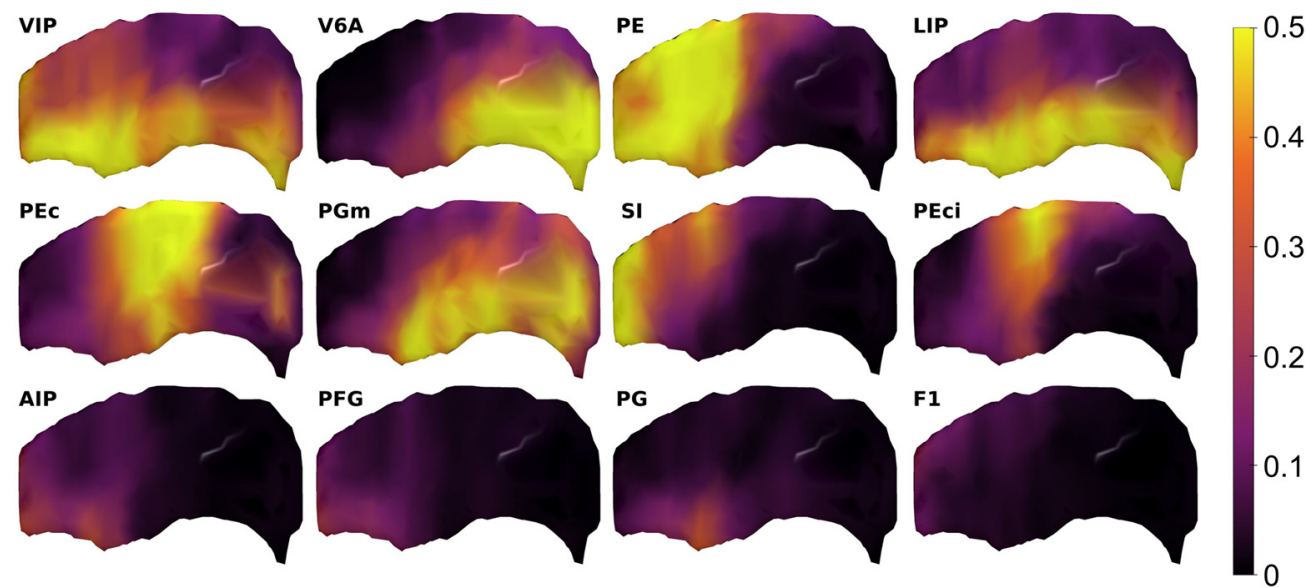

Figure 12. Spatial distribution of the IPS connectivity estimated from DW-MRI along 34 dorsal, middle, and ventral A-P sectors of the $\mathrm{db}$-IPS, for the 12 cortical ROls displaying the strongest estimated connectivity with the db-IPS (Fig. 11). The yellow and orange regions highlight the IPS locations with the strongest estimated connectivity for the corresponding cortical areas. 
along both the A-P and D-V dimensions is offered by $\mathrm{PEc}$, whose connectivity is strongest with the dorsal and intermediate part of the bank. The connectivity of $P G m$ resembles that of $V 6 A$, but it is weaker and more diffuse in the A-P extent of the ventral part of the intermediate sectors. Area $\mathrm{SI}$ is strongly connected with the D-V extent of the rostralmost part of the bank, while the connections of PEci are more selective, since they occur mainly with the central part of the bank, are stronger dorsally and fade away moving ventrally, anteriorly and posteriorly. The inferior parietal areas AIP, PFG, and PG show a weak connectivity with the anterior part of the ventral sector of the bank, while motor cortex (M1) is weakly connected with its anterodorsal sector.

\section{Discussion}

The results of this study provide solid support for a parcellation of the db-IPS into a rostral area PEip and a caudal area MIP, based on corticospinal projections, as well as for an internal subdivision of both areas into an anterior and posterior sector. Our data also show A-P and D-V connectional gradients, matching those of functional properties described by electrophysiological studies. In the A-P extent of the SPL Crammond and Kalaska (1989) and Burbaud et al. (1991) showed that activity in area PE is mostly related to somatosensory and somatomotor functions, while Colby and Duhamel (1991) in MIP described a set visuomotor functions. A combined anatomo-functional analysis of the parieto-frontal system (Johnson et al., 1996) in monkeys revealed that reachingrelated neurons displaying signal-related, set-related, movement-related, and positional-related activity decreased in numbers moving from ventral to dorsal in MIP, up to area PE. A similar trend was found in the A-P dimension of the frontal lobe, from F7 to F2 and MI. Furthermore, parietal and frontal regions displaying similar activity types were linked by direct corticocortical connections.

\section{Cortical connections of the $\mathrm{db}$-IPS}

Our data are in line but also extend data from Bakola et al. (2017), where MIP defined myeloarchitectonically extends rostrally up to the A-P level of the caudal end of the central sulcus, thus including the caudalmost part of the corticospinal sector of the db-IPS.

Our tracer injections in MIP show a relatively strong connectivity with visuomotor areas V6A, PEc, PEip, and F2. Weaker connections involve the IPL visuomotor area PG, area PGop and M1. Furthermore, aMIP, when compared with pMIP, shows stronger connectivity with area PE and visuomotor area PGm, a weaker one with somatosensoryrelated area PEci. This connectivity pattern of MIP conforms to that reported by Bakola et al. (2017) for the caudal part of this area. Furthermore, indirect support for this connectivity scheme and for the reciprocity characterizing MIP connections comes from studies in which this area was labeled after retrograde tracer injections in V6A (Marconi et al., 2001; Gamberini et al., 2009; Passarelli et al., 2011), PEc and PE (Marconi et al., 2001; Bakola et al., 2010, 2013), PGm (Passarelli et al., 2018), PG (Rozzi et al., 2006), and F2 (Johnson et al., 1996; Matelli et al., 1998; Marconi et al., 2001; Tanné-Gariépy et al., 2002). Thus, the connectivity of MIP provides a neural substrate for the visuomotor control of reaching and eye-hand coordination, since it can serve as interface between the premotor areas of the frontal lobe and the parieto-occipital areas V6A and PEc, where neurons combine in a directionally-congruent fashion eye-related and hand-related positional and movement signals within their directional tuning fields (BattagliaMayer et al., 2000, 2001). Interestingly, similar inputs to MIP come from PGm $(7 \mathrm{~m})$, where individual neurons also integrate visual, eye and hand information (Ferraina et al., 1997a,b).

A model relevant to eye-hand coordination (Mascaro et al., 2003) integrating inputs from the retinal position of the target with eye and hand position shows that both feedforward and recurrent interactions of these signals account very well for the experimentally observed tuning fields of parietal neurons. In this model, the representation of directional variables concerning hand and eye movement emerges from Hebbian synaptic plasticity alone (see Battaglia-Mayer and Caminiti, 2002, 2018; Battaglia-Mayer et al., 2015).

Our data also show that area PEip displays as unifying connectional features a robust connectivity with the cervical spinal cord and the hand field of M1. Strong connections with area PE and with visuomotor hand-related area PFG (Ferrari-Toniolo et al., 2015), bimodal visual and somatosensory area VIP, and area F4 further characterize PEip. The caudal part of PEip also displays connections with V6A and F2 and a connectivity pattern with areas PEci, PEc, and PG quantitatively similar to that of aMIP. In contrast, aPEip displays connections with the arm/hand field of $\mathrm{SI}$, the hand-related area AIP and a strong link with PGop, whose function remains unknown. The connectivity observed after tracer injections in pPEip and aPEip is very similar to that observed by Bakola et al. (2017) after an injection in rostral myeloarchitectonic area MIP and in area PEip, respectively. Connections with PEip have been observed after retrograde tracer injections in areas V6A (Gamberini et al., 2009), PE (Bakola et al., 2013), PFG (Rozzi et al., 2006), AIP (Borra et al., 2008; Lanzilotto et al., 2019), F2 (Johnson et al., 1996; Matelli et al., 1998; Tanné-Gariépy et al., 2002), and M1 (Strick and Kim, 1978; Matelli et al., 1986; Hatanaka et al., 2001). This connectivity suggests a role of PEip in sensorimotor control of hand movements. Indeed, PEip as a whole coincides with the db-IPS sector hosting corticospinal neurons projecting to distal hand muscles motorneurons (Rathelot et al., 2017), as well as neurons with somatosensory receptive fields on the hand (Iwamura et al., 1994; Iwamura, 2000; Seelke et al., 2012). The posterior part of PEip could also correspond to the sector hosting neurons with bimodal, visual and somatosensory receptive field centered on the hand (Iriki et al., 1996) while anterior PEip to the sector rich in grasping-related neurons (Gardner et al., 2007). The connectional differences between the posterior and the anterior part of PEip, suggest for the former a role in visuomotor and somatomotor control of hand and arm movements, and for the latter a role in somatomotor control of hand actions. 


\section{Diffusion-based connectivity estimations}

We have used state-of-the-art tractography algorithm and microstructure method to estimate the intra-axonal MRI signal fraction associated with streamlines, instead of using their number. This reduced density biases associated with white matter bundle features, such as length, curvature, and size, making tractography more quantitative (Girard et al., 2014; Daducci, et al., 2015). This goal was achieved by using a model of tissue microstructure (Stick-Zeppelin-Ball model; Panagiotaki et al., 2012; Daducci et al., 2015) to explain the measured DW-MRI signal from the streamlines, by removing or penalizing redundant or inaccurate trajectories. In a previous study, Girard et al. (2020) compared various diffusion-based connectivity estimation approaches in the monkey brain and showed that this model had strong performances in the prediction of parieto-frontal binary connectivity (sensitivity and specificity). Moreover, the model provided the highest fraction of valid connectivity weight among methods with high sensitivity and specificity.

In the connectivity network emerging after the four injections made within the db-IPS, our results showed an increased sensitivity of 0.96 (from 0.79 ) and a decreased specificity of 0.55 (from 0.60 ), as compared with the analysis of the parieto-frontal network we made before (Girard et al., 2020). Overall, this resulted in an increased Youden's index (sensitivity + specificity -1 ; Youden, 1950) to 0.51 versus the 0.39 reported in Girard et al. (2020). Moreover, in the network studied here, we found $90.4 \%$ of the connectivity weights between ROls with reported non-zero labeled cell count, $10.2 \%$ more than in Girard et al. (2020). This suggests a strong predictive power of tractography for the connectivity of the monkeys IPS, which was also confirmed by the lack of connections with prefrontal areas shown by both histologic and tractography results.

In addition to the rostro-caudal gradients evidenced by the tracer injections, the tractography estimated connectivity showed along the $\mathrm{db}$-IPS clear D-V gradients which would have been difficult to demonstrate based on tracer injections. These consisted in a preferential connectivity of ventral sectors of the bank with visuomotor areas V6A, PGm, and LIP and a preferential connectivity of middle and dorsal sectors with SI, PE, PEci, PEc, thus matching the increase in visually responsive neurons moving from dorsal to ventral in the bank (Colby and Duhamel, 1991; Johnson et al., 1996; see Battaglia-Mayer et al., 2016). D-V chemoarchitectonic differences within the db-IPS, waiting for functional and/or connectional correlation, have been observed based on receptor autoradiography (Niu et al., 2020).

Our overall correlation of the diffusion-based connectivity and of the RLCs distribution $(r=0.65)$ goes in line with the results $(r=0.59)$ reported by Donahue et al. (2016). These authors studied the predictive power of tractography for connection weights derived from 29 retrograde tracer injections and 91 areas, reported by Markov et al. (2014). Although we have used different tractography algorithms and connectivity weights estimation from DWMRI, both Donahue et al. (2016) and our study show that tractography can indeed estimate structural connectivity weights correlated with the number of measured labeled cells connecting cortical areas.

\section{Tractography misestimated connections}

Although tractography produces weighted connectivity proportions showing a good correlation with the proportions of labeled cells, and that most of the weights are in connections with non-zero measured labeled cell count, some connection weights were misestimated.

The source of these misestimations can be related, in part, to the unidirectional labeling of cells from retrograde axonal tracing used in this study. Thus, asymmetry in the afferent and efferent axon densities of a fascicle could result in a mismatch between the two techniques. The diffusion-based connectivity was estimated from ROls in the $\mathrm{db}-$ IPS that were larger than the injection site of tracers, thus reporting the connectivity of a broader sector. Moreover, the intricate white matter geometries and configurations, such as crossing and kissing, could have generated incorrect orientations and erroneous trajectories (Jeurissen et al., 2019; Girard et al., 2020). Finally, the accuracy of diffusion-based connectivity is limited by the model of the white matter used, which can fail to accurately model the diffusion signal in intricate microstructure environments (Jelescu et al., 2020). Future work should target analysis of ROls with misestimated connectivity, using DW-MRI and bidirectional tracing data of the same animal.

\section{References}

Ahmed B, Cordery PM, McLelland D, Bair W, Krug K (2012) Longrange clustered connections within extrastriate visual area V5/MT of the rhesus macaque. Cereb Cortex 22:60-73.

Ambrosen KS, Eskildsen SF, Hinne M, Krug K, Lundell H, Schmidt MN, van Gerven MAJ, Mørup M, Dyrby TB (2020) Validation of structural brain connectivity networks: the impact of scanning parameters. Neuroimage 204:116-207.

Aydogan DB, Jacobs R, Dulawa S, Thompson SL, Francois MC, Toga AW, Dong H, Knowles JA, Shi Y (2018) When tractography meets tracer injections: a systematic study of trends and variation sources of diffusion-based connectivity. Brain Struct Funct 223:2841-2858.

Azadbakht H, Parkes LM, Haroon HA, Augath M, Logothetis NK, de Crespigny A, D'Arceuil HE, Parker GJ (2015) Validation of high-resolution tractography against in vivo tracing in the macaque visual cortex. Cereb Cortex 25:4299-4309.

Bakola S, Gamberini M, Passarelli L, Fattori P, Galletti C (2010) Cortical connections of parietal field PEc in the macaque: linking vision and somatic sensation for the control of limb action. Cereb Cortex 20:2592-2604

Bakola S, Passarelli L, Gamberini M, Fattori P, Galletti C (2013) Cortical connectivity suggests a role in limb coordination for macaque area PE of the superior parietal cortex. J Neurosci 33:66486658.

Bakola S, Passarelli L, Huynh T, Impieri D, Worthy KH, Fattori P, Galletti C, Burman KJ, Rosa MGP (2017) Cortical afferents and myeloarchitecture distinguish the medial intraparietal area (MIP) from neighboring subdivisions of the macaque cortex. eNeuro 4: ENEURO.0344-17.2017.

Bálint R (1909) Seelenlähmung des "Schauens", optische Ataxia, räumliche Störung der Aufmerksamkeit. Mschr Psychiat Neurol 25:51-66. 
Batista AP, Buneo CA, Snyder LH, Andersen RA (1999) Reach plans in eye-centered coordinates. Science 285:257-260.

Battaglia-Mayer A, Caminiti R (2002) Optic ataxia as a result of the breakdown of the global tuning fields of parietal neurones. Brain 125:25-237.

Battaglia-Mayer A, Caminiti R (2018) Parieto-frontal networks for eye-hand coordination and movements. Handb Clin Neurol 151:499-524.

Battaglia-Mayer A, Caminiti R (2019) Corticocortical Systems Underlying High-Order Motor Control. J Neurosci 39:4404-4421.

Battaglia-Mayer A, Ferraina S, Mitsuda T, Marconi B, Genovesio A, Onorati P, Lacquaniti F, Caminiti R (2000) Early coding of reaching in the parieto-occipital cortex. J Neurophysiol 83:2374-2391.

Battaglia-Mayer A, Ferraina S, Genovesio A, Marconi B, Squatrito S, Molinari M, Lacquaniti F, Caminiti R (2001) Eye-hand coordination during reaching. II. An analysis of the relationships between visuomanual signals in parietal cortex and parieto-frontal association projections. Cereb Cortex 11:528-544.

Battaglia-Mayer A, Ferrari-Toniolo S, Visco-Comandini F (2015) Timing and communication of parietal cortex for visuomotor control. Curr Opin Neurobiol 33:103-109.

Battaglia-Mayer A, Babicola L, Satta E (2016) Parieto-frontal gradients and domains underlying eye and hand operations in the action space. Neuroscience 334:76-92.

Belmalih A, Borra E, Contini M, Gerbella M, Rozzi S, Luppino G (2009) Multimodal architectonic subdivision of the rostral part (area F5) of the macaque ventral premotor cortex. J Comp Neurol 512:183-217.

Blatt GJ, Andersen RA, Stoner GR (1990) Visual receptive field organization and cortico-cortical connections of the lateral intraparietal area (area LIP) in the macaque. J Comp Neurol 299:421-445.

Borra E, Belmalih A, Calzavara R, Gerbella M, Murata A, Rozzi S, Luppino G (2008) Cortical connections of the macaque anterior intraparietal (AIP) area. Cereb Cortex 18:1094-1111.

Borra E, Belmalih A, Gerbella M, Rozzi S, Luppino G (2010) Projections of the hand field of the macaque ventral premotor area F5 to the brainstem and spinal cord. J Comp Neurol 518:25702591.

Burbaud P, Doegle C, Gross C, Bioulac B (1991) A quantitative study of neuronal discharge in areas 5,2 , and 4 of the monkey during fast arm movements. J Neurophysiol 66:429-443.

Calabrese E, Badea A, Cofer G, Qi Y, Johnson GA (2015) A Diffusion MRI tractography connectome of the mouse brain and comparison with neuronal tracer data. Cereb Cortex 25:4628-4637.

Caminiti R, Johnson PB, Galli C, Ferraina S, Burnod Y (1991) Making arm movements within different parts of space: the premotor and motor cortical representation of a coordinate system for reaching to visual targets. J Neurosci 11:1182-1197.

Caminiti R, Ferraina S, Johnson PB (1996) The sources of visual information to the primate frontal lobe: a novel role for the superior parietal lobule. Cereb Cortex 6:319-328.

Caminiti R, Borra E, Visco-Comandini F, Battaglia-Mayer A, Averbeck BB, Luppino G (2018) Computational architecture of the parieto-frontal network underlying cognitive-motor control in monkeys. eNeuro 4:ENEURO.0306-16.2017.

Carmichael ST, Price JL (1994) Architectonic subdivision of the orbital and medial prefrontal cortex in the macaque monkey. J Comp Neurol 346:366-402.

Chafee MV, Goldman-Rakic PS (1998) Matching patterns of activity in primate prefrontal area $8 \mathrm{a}$ and parietal area 7ip neurons during a spatial working memory task. J Neurophysiol 79:2919-2940.

Chafee MV, Goldman-Rakic PS (2000) Inactivation of parietal and prefrontal cortex reveals interdependence of neural activity during memory-guided saccades. J Neurophysiol 83:1550-1566.

Colby CL, Duhamel JR (1991) Heterogeneity of extrastriate visual areas and multiple parietal areas in the macaque monkey. Neuropsychologia 29:517-537.

Colby CL, Gattass R, Olson CR, Gross CG (1988) Topographical organization of cortical afferents to extrastriate visual area $P O$ in the macaque: a dual tracer study. J Comp Neurol 269:392-413.
Condé F (1987) Further studies on the use of the fluorescent tracers fast blue and diamidino yellow: effective uptake area and cellular storage sites. J Neurosci Methods 21:31-43.

Crammond DJ, Kalaska JF (1989) Neuronal activity in primate parietal cortex area 5 varies with intended movement direction during an instructed-delay period. Exp Brain Res 76:458-462.

Daducci A, Dal Palù A, Lemkaddem A, Thiran JP (2015) COMMIT: convex optimization modeling for micro-structure informed tractography. IEEE Trans Med Imaging 34:246-257.

Dauguet J, Peled S, Berezovskii V, Delzescaux T, Warfield SK, Born R, Westin CF (2007) Comparison of fiber tracts derived from invivo DTI tractography with $3 \mathrm{D}$ histological neural tract tracer reconstruction on a macaque brain. Neuroimage 37:530-538.

Delettre C, Messé A, Dell LA, Foubet O, Heuer K, Larrat B, Meriaux S, Mangin JF, Reillo I, de Juan Romero C, Borrell V, Toro R, Hilgetag CC (2019) Comparison between diffusion MRI tractography and histological tract-tracing of cortico-cortical structural connectivity in the ferret brain. Netw Neurosci 3:1038-1050.

Demelio S, Bettio F, Gobbetti E, Luppino G (2001) Three-dimensional reconstruction and visualization of the cerebral cortex in primates. In: Data visualization 2001. Proceedings of the joint eurographics and IEEE TCVG symposium on visualization (Ebert D, Favre J, Peikert R, eds). Ascona: Springer.

Donahue CJ, Sotiropoulos SN, Jbabdi S, Hernandez-Fernandez M, Behrens TE, Dyrby TB, Coalson T, Kennedy H, Knoblauch K, Van Essen DC, GlasserMF (2016) Using diffusion tractography to predict cortical connection strength and distance: a quantitative comparison with tracers in the monkey. J Neurosci 36:6758-6770.

Dyrby TB, Søgaard LV, Parker GJ, Alexander DC, Lind NM, Baaré WF, Hay-Schmidt A, Eriksen N, Pakkenberg B, Paulson OB (2007) Validation of in vitro probabilistic tractography. Neuroimage 37:1267-1277.

Dyrby TB, Baaré WF, Alexander DC, Jelsing J, Garde E, Søgaard LV (2011) An ex vivo imaging pipeline for producing high-quality and high-resolution diffusion-weighted imaging datasets. Hum Brain Mapp 32:544-563.

Ferraina S, Garasto MR, Battaglia-Mayer A, Ferraresi P, Johnson PB, Lacquaniti F, Caminiti R (1997a) Visual control of hand-reaching movement: activity in parietal area $7 \mathrm{~m}$. Eur J Neurosci 9:10901095.

Ferraina S, Johnson PB, Garasto MR, Battaglia-Mayer A, Ercolani L, Bianchi L, Lacquaniti F, Caminiti R (1997b) Combination of hand and gaze signals during reaching:activity in parietal area $7 \mathrm{~m}$ of the monkey. J Neurophysiol 77:1034-1038.

Ferrari-Toniolo S, Visco-Comandini F, Papazachariadis O, Caminiti R, Battaglia-Mayer A (2015) Posterior parietal cortex encoding of dynamic hand force underlying hand-object interaction. J Neurosci 35:10899-10910.

Fogassi L, Raos V, Franchi G, Gallese V, Luppino G, Matelli M (1999) Visual responses in the dorsal premotor area F2 of the macaque monkey. Exp Brain Res 128:194-199.

Gamberini M, Passarelli L, Fattori P, Zucchelli M, Bakola S, Luppino G, Galletti C (2009) Cortical connections of the visuomotor parietooccipital area V6Ad of the macaque monkey. J Comp Neurol 513:622-642.

Gardner EP, Babu KS, Reitzen SD, Ghosh S, Brown AS, Chen J, Hall AL, Herzlinger MD, Kohlenstein JB, Ro JY (2007) Neurophysiology of prehension. I. Posterior parietal cortex and object-oriented hand behaviors. J Neurophysiol 97:387-406.

Garyfallidis E, Brett M, Amirbekian B, Rokem A, van der Walt S, Descoteaux M, Nimmo-Smith I (2014) Dipy, a library for the analysis of diffusion MRI data. Front Neuroinform 8:8.

Gerbella M, Belmalih A, Borra E, Rozzi S, Luppino G (2007) Multimodal architectonic subdivision of the caudal ventrolateral prefrontal cortex of the macaque monkey. Brain Struct Funct 212:269-301.

Girard G, Whittingstall K, Deriche R, Descoteaux M (2014) Towards quantitative connectivity analysis: reducing tractography biases. Neuroimage 98:266-278. 
Girard G, Caminiti R, Battaglia-Mayer A, St-Onge E, Ambrosen KS, Eskildsen SF, Krug K, Dyrby TB, Descoteaux M, Thiran JP, Innocenti GM (2020) On the cortical connectivity in the macaque brain: a comparison of diffusion tractography and histological tracing data. Neuroimage 221:117201.

Gregoriou GG, Borra E, Matelli M, Luppino G (2006) Architectonic organization of the inferior parietal convexity of the macaque monkey. J Comp Neurol 496:422-451.

Gyengesi E, Calabrese E, Sherrier MC, Johnson GA, Paxinos G, Watson C (2015) Semi-automated 3D segmentation of major tracts in the rat brain: comparing DTI with standard histological methods. Brain Struct Funct 219:539-550.

Hatanaka N, Nambu A, Yamashita A, Takada M, Tokuno H (2001) Somatotopic arrangement and corticocortical inputs of the hindlimb region of the primary motor cortex in the macaque monkey. Neurosci Res 40:9-22.

Iriki A, Tanaka M, Iwamura Y (1996) Coding of modified body schema during tool use by macaque postcentral neurones. Neuroreport 7:2325-2330.

Iwamura Y (2000) Bilateral receptive field neurons and callosal connections in the somatosensory cortex. Philos Trans R Soc Lond B Biol Sci 355:267-273.

Iwamura Y, Iriki A, Tanaka M (1994) Bilateral hand representation in the postcentral somatosensory cortex. Nature 369:554-556.

Jbabdi S, Sotiropoulos SN, Haber SN, Van Essen DC, Behrens TE (2015) Measuring macroscopic brain connections in vivo. Nat Neurosci 18:1546-1555.

Jelescu IO, Palombo M, Bagnato F, Schilling KG (2020) Challenges for biophysical modeling of microstructure. J Neurosci Methods 344:108861.

Jeurissen B, Tournier JD, Dhollander T, Connelly A, Sijbers J (2014) Multi-tissue constrained spherical deconvolution for improved analysis of multi-shell diffusion MRI data. Neuroimage 103:411426.

Jeurissen B, Descoteaux M, Mori S, Leemans A (2019) Diffusion MRI fiber tractography of the brain. NMR Biomed 32:e3785.

Johnson PB, Ferraina S, Bianchi L, Caminiti R (1996) Cortical networks for visual reaching: physiological and anatomical organization of frontal and parietal lobe arm regions. Cereb Cortex 6:102119.

Jones DK, Knösche TR, Turner R (2013) White matter integrity, fiber count, and other fallacies: the do's and don'ts of diffusion MRI. Neuroimage 73:239-254.

Knösche TR, Anwander A, Liptrot M, Dyrby TB (2015) Validation of tractography: comparison with manganese tracing. Hum Brain Map 36:4116-4134.

Kuypers HGJM, Huisman AM (1984) Fluorescent neuronal tracers. Adv Cell Neurobiol 5:307-340.

Lacquaniti F, Guigon E, Bianchi L, Ferraina S, Caminiti R (1995) Representing spatial information for limb movement: the role of area 5 in the monkey. Cereb Cortex 5:391-409.

Lanzilotto M, Ferroni CG, Livi A, Gerbella M, Maranesi M, Borra E, Passarelli L, Gamberini M, Fogassi L, Bonini L, Orban GA (2019) Anterior intraparietal area: a hub in the observed manipulative action network. Cereb Cortex 29:1816-1833.

Luppino G, Matelli M, Camarda R, Rizzolatti G (1994) Corticospinal projections from mesial frontal and cingulate areas in the monkey. Neuroreport 5:2545-2548.

Luppino G, Ben Hamed S, Gamberini M, Matelli M, Galletti C (2005) Occipital (V6) and parietal (V6A) areas in the anterior wall of the parieto-occipital sulcus of the macaque: a cytoarchitectonic study. Eur J Neurosci 21:3056-3076.

Maier-Hein KH, Neher PF, Houde JC, Côté MA, Garyfallidis E, Zhong J, Chamberland M, Yeh FC, Lin YC, Ji Q, Reddick WE, Glass JO, Chen DQ, Feng Y, Gao C, Wu Y, Ma J, He R, Li Q, Westin CF, et al. (2017) The challenge of mapping the human connectome based on diffusion tractography. Nat Commun 8:1349.

Marconi B, Genovesio A, Battaglia-Mayer A, Ferraina S, Squatrito S, Molinari M, Lacquaniti F, Caminiti R (2001) Eye-hand coordination during reaching. I. Anatomical relationships between parietal and frontal cortex. Cereb Cortex 11:513-527.

Markov NT, Ercsey-Ravasz MM, Ribeiro Gomes AR, Lamy C, Magrou L, Vezoli J, Misery P, Falchier A, Quilodran R, Gariel MA, Sallet J, Gamanut R, Huissoud C, Clavagnier S, Giroud P, SappeyMarinier D, Barone P, Dehay C, Toroczkai Z, Knoblauch K, et al. (2014) A weighted and directed interareal connectivity matrix for macaque cerebral cortex. Cereb Cortex 24:17-36.

Mascaro M, Battaglia-Mayer A, Nasi L, Amit DJ, Caminiti R (2003) The eye and the hand: neural mechanisms and network models for oculomanual coordination in parietal cortex. Cereb Cortex 13:1276-1286.

Matelli M, Luppino G, Rizzolatti G (1985) Patterns of cytochrome oxidase activity in the frontal agranular cortex of the macaque monkey. Behav Brain Res 18:125-136.

Matelli M, Camarda R, Glickstein M, Rizzolatti G (1986) Afferent and efferent projections of the inferior area 6 in the macaque monkey. J Comp Neurol 251:281-298.

Matelli M, Luppino G, Rizzolatti G (1991) Architecture of superior and mesial area 6 and the adjacent cingulate cortex in the macaque monkey. J Comp Neurol 311:445-462.

Matelli M, Govoni P, Galletti C, Kutz DF, Luppino G (1998) Superior area 6 afferents from the superior parietal lobule in the macaque monkey. J Comp Neurol 402:327-352.

Mesulam MM (1982) Principles of horseradish peroxidase neurohistochemistry and their applications for tracing neural pathway. In: Tracing neural connections with horseradish peroxidase. (Mesulam MM, ed), pp 11-52. Chichester: Wiley.

Niu M, Impieri D, Rapan L, Funck T, Palomero-Gallagher N, Zilles K (2020) Receptor-driven, multimodal mapping of cortical areas in the macaque monkey intraparietal sulcus. Elife 9:e55979.

Panagiotaki E, Schneider T, Siow B, Hall MG, Lythgoe MF, Alexander DC (2012) Compartment models of the diffusion MR signal in brain white matter: a taxonomy and comparison. Neuroimage 59:2241-2254.

Pandya DN, Seltzer B (1982) Intrinsic connections and architectonics of posterior parietal cortex in the rhesus monkey. J Comp Neurol 204:196-210.

Passarelli L, Rosa MG, Gamberini M, Bakola S, Burman KJ, Fattori P, Galletti C (2011) Cortical connections of area V6Av in the macaque: a visual-input node to the eye/hand coordination system. J Neurosci 31:1790-1801.

Passarelli L, Rosa MGP, Bakola S, Gamberini M, Worthy KH, Fattori P, Galletti C (2018) Uniformity and diversity of cortical projections to precuneate areas in the macaque monkey: what defines area PGm? Cereb Cortex 28:1700-1717.

Paxinos G, Huang X, Petrides M, Toga AW (2009) The rhesus monkey brain in stereotaxic coordinates, Ed 2. San Diego: Academic Press.

Rathelot JA, Strick PL (2009) Subdivisions of primary motor cortex based on cortico-motoneuronal cells. Proc Natl Acad Sci USA 106:918-923.

Rathelot JA, Dum RP, Strick PL (2017) Posterior parietal cortex contains a command apparatus for hand movements. Proc Natl Acad Sci USA 114:4255-4260.

Rossetti Y, Pisella L (2018) Optic ataxia: beyond the dorsal stream cliché. Handb Clin Neurol 151:225-247.

Rozzi S, Calzavara R, Belmalih A, Borra E, Gregoriou GG, Matelli M, Luppino $\mathrm{G}$ (2006) Cortical connections of the inferior parietal cortical convexity of the macaque monkey. Cereb Cortex 16:13891417.

Saleem KS, Logothetis NK (2012) A Combined MRI and histology atlas of the rhesus monkey brain in stereotaxic coordinates, Ed 2. London: Elsevier Science.

Saleem KS, Miller B, Price JL (2014) Subdivisions and connectional networks of the lateral prefrontal cortex in the macaque monkey. $J$ Comp Neurol 522:1641-1690.

Schilling KG, Nath V, Hansen C, Parvathaneni P, Blaber J, Gao Y, Neher P, Aydogan DB, Shi Y, Ocampo-Pineda M, Schiavi S, Daducci A, Girard G, Barakovic M, Rafael-Patino J, Romascano D, 
Rensonnet G, Pizzolato M, Bates A, Fischi E, et al. (2019a) Limits to anatomical accuracy of diffusion tractography using modern approaches. Neuroimage 185:1-11.

Schilling KG, Gao Y, Stepniewska I, Janve V, Landman BA, Anderson AW (2019b) Anatomical accuracy of standard-practice tractography algorithms in the motor system - a histological validation in the squirrel monkey brain. Magn Reson Imaging 55:7-25.

Seehaus AK, Roebroeck A, Chiry O, Kim DS, Ronen I, Bratzke H, Goebel R, Galuske RA (2013) Histological validation of DW-MRI tractography in human postmortem tissue. Cereb Cortex 23:442450.

Seelke AM, Padberg JJ, Disbrow E, Purnell SM, Recanzone G, Krubitzer L (2012) Topographic maps within Brodmann's area 5 of macaque monkeys. Cereb Cortex 22:1834-1850.

Strick PL, Kim CC (1978) Input to primate motor cortex from posterior parietal cortex (area 5). I. Demonstration by retrograde transport. Brain Res 157:325-330.

Tanné-Gariépy J, Rouiller EM, Boussaoud D (2002) Parietal inputs to dorsal versus ventral premotor areas in the macaque monkey: evidence for largely segregated visuomotor pathways. Exp Brain Res 145:91-103.
Thomas C, Ye FQ, Irfanoglu MO, Modi P, Saleem KS, Leopold DA, Pierpaoli C (2014) Anatomical accuracy of brain connections derived from diffusion MRI tractography is inherently limited. Proc Natl Acad Sci USA 111:16574-16579.

Tournier JD, Smith R, Raffelt D, Tabbara R, Dhollander T, Pietsch M, Christiaens D, Jeurissen B, Yeh CH, Connelly A (2019) MRtrix3: a fast, flexible and open software framework for medical image processing and visualisation. Neuroimage 202:116137.

van den Heuvel MP, de Reus MA, Feldman Barrett L, Scholtens LH, Coopmans FM, Schmidt R, Preuss TM, Rilling JK, Li L (2015) Comparison of diffusion tractography and tract-tracing measures of connectivity strength in rhesus macaque connectome. Hum Brain Mapp 36:3064-3075.

Van Essen DC, Jbabdi S, Sotiropoulos SN, Chen C, Dikranian K, Coalson T, Harwell J, Glasser MF (2014) Mapping connections in humans and non-human primates: aspirations and challenges for diffusion imaging. Diffusion MRI 337-358.

Youden WJ (1950) Index for rating diagnostic tests. Cancer 3:32-35.

Zhang Y, Brady M, Smith S (2001) Segmentation of brain MR images through a hidden Markov random field model and the expectationmaximization algorithm. IEEE Trans Med Imaging 20:45-57. 